\title{
Cholinergic, Glutamatergic, and GABAergic Neurons of the Pedunculopontine Tegmental Nucleus Have Distinct Effects on Sleep/Wake Behavior in Mice
}

\author{
Daniel Kroeger, ${ }^{1}$ Loris L. Ferrari, ${ }^{1}$ Gaetan Petit, ${ }^{1,2}$ Carrie E. Mahoney, ${ }^{1}$ Patrick M. Fuller, ${ }^{1}$ Elda Arrigoni, ${ }^{1}$ \\ and ${ }^{-T h o m a s ~ E . ~ S c a m m e l l ~}{ }^{1}$ \\ ${ }^{1}$ Department of Neurology, Beth Israel Deaconess Medical Center and Harvard Medical School, Boston, Massachusetts 02215, and 2École Polytechnique \\ Fédérale de Lausanne, CH-1015 Lausanne, Switzerland
}

The pedunculopontine tegmental (PPT) nucleus has long been implicated in the regulation of cortical activity and behavioral states, including rapid eye-movement (REM) sleep. For example, electrical stimulation of the PPT region during sleep leads to rapid awakening, whereas lesions of the PPT in cats reduce REM sleep. Though these effects have been linked with the activity of cholinergic PPT neurons, the PPT also includes intermingled glutamatergic and GABAergic cell populations, and the precise roles of cholinergic, glutamatergic, and GABAergic PPT cell groups in regulating cortical activity and behavioral state remain unknown. Using a chemogenetic approach in three Cre-driver mouse lines, we found that selective activation of glutamatergic PPT neurons induced prolonged cortical activation and behavioral wakefulness, whereas inhibition reduced wakefulness and increased non-REM (NREM) sleep. Activation of cholinergic PPT neurons suppressed lower-frequency electroencephalogram rhythms during NREM sleep. Last, activation of GABAergic PPT neurons slightly reduced REM sleep. These findings reveal that glutamatergic, cholinergic, and GABAergic PPT neurons differentially influence cortical activity and sleep/wake states.

Key words: chemogenetic; mouse; PPT; sleep

\section{Significance Statement}

More than 40 million Americans suffer from chronic sleep disruption, and the development of effective treatments requires a more detailed understanding of the neuronal mechanisms controlling sleep and arousal. The pedunculopontine tegmental (PPT) nucleus has long been considered a key site for regulating wakefulness and REM sleep. This is mainly because of the cholinergic neurons contained in the PPT nucleus. However, the PPT nucleus also contains glutamatergic and GABAergic neurons that likely contribute to the regulation of cortical activity and sleep-wake states. The chemogenetic experiments in the present study reveal that cholinergic, glutamatergic, and GABAergic PPT neurons each have distinct effects on sleep/wake behavior, improving our understanding of how the PPT nucleus regulates cortical activity and behavioral states.

\section{Introduction}

The pedunculopontine tegmental (PPT) and laterodorsal tegmental (LDT) nuclei were among the first brain regions hypothesized to promote brain activation (el Mansari et al., 1989; Steriade et al., 1990). The PPT and LDT nuclei are anatomically

\footnotetext{
Received April 28, 2016; revised Dec. 10, 2016; accepted Dec. 21, 2016.

Author contributions: D.K. and T.E.S. designed research; D.K., L.L.F., G.P., and C.E.M. performed research; P.M.F. contributed unpublished reagents/analytic tools; D.K., L.L.F., and E.A. analyzed data; D.K., P.M.F., E.A., and T.E.S. wrote the paper.

This work was supported by National Institutes of Health Grants HL095491 and HL007901.

The authors declare no competing financial interests.

Correspondence should be addressed to Thomas E. Scammell, MD, Beth Israel Deaconess Medical Center, 330 Brookline Avenue, Boston, MA 02215. E-mail: tscammel@bidmc.harvard.edu.

DOI:10.1523/JNEUROSCI.1405-16.2016

Copyright $\odot 2017$ the authors $\quad 0270-6474 / 17 / 371352-15 \$ 15.00 / 0$
}

defined as clusters of large cholinergic neurons at the junction of the midbrain and pons (Saper and Loewy, 1982; Armstrong et al., 1983), but they also contain intermixed but separate populations of glutamatergic and GABAergic neurons (Ford et al., 1995; Mena-Segovia et al., 2009; Wang and Morales, 2009). PPT/LDT neurons innervate many arousal-promoting brain regions, including the ventral tegmental area (VTA), the lateral hypothalamus, the basal forebrain, the frontal cortex, and many thalamic nuclei (Satoh and Fibiger, 1986; Woolf and Butcher, 1986; Scarnati et al., 1987; Hallanger and Wainer, 1988; Oakman et al., 1995). In addition, high-frequency electrical stimulation of the PPT in sleeping and anesthetized cats induces fast electroencephalogram (EEG) patterns similar to those seen during wake (Steriade et al., 1993; Seigneur et al., 2006). 
Just how the PPT promotes wake remains unclear. One idea stresses the reciprocal connections to midbrain dopaminergic nuclei, such as the substantia nigra (SN) and VTA, which receive excitatory input from the PPT (Dautan et al., 2016) and play a key role in modulating arousal (Eban-Rothschild et al., 2016). Another model stresses the influence of cholinergic PPT/LDT projections on thalamic activity (Steriade et al., 1991). During wakefulness, acetylcholine facilitates thalamocortical signaling by directly exciting thalamocortical relay neurons while reducing activity in the reticular nucleus of the thalamus, which inhibits thalamocortical neurons. At the onset of nonrapid eye movement (NREM) sleep, reduced cholinergic activity has the opposite effects, and thalamocortical neurons are hyperpolarized, resulting in a clock-like burst firing mode incompatible with the relay of information to and from the cortex. In the absence of thalamic input, cortical neurons enter a state of synchronized activity resulting in the characteristic patterns of NREM sleep. PPT neurons also innervate the basal forebrain, and thus the PPT is well positioned to influence arousal through effects on a variety of subcortical regions.

In addition to influencing wakefulness, the PPT/LDT and other pontine regions are implicated in the control of rapid eye movement (REM) sleep. Injection of cholinergic agonists, such as carbachol, into the pons of cats or rats triggers a long-lasting state very similar to REM sleep (Baghdoyan et al., 1984; Shiromani et al., 1996; Kubin, 2001). In addition, low-amplitude electrical stimulation of the LDT can increase REM sleep (Thakkar et al., 1996), whereas large neurotoxic lesions that include the PPT/ LDT decrease REM sleep for several weeks in cats (Webster and Jones, 1988). Moreover, intracellular and juxtacellular recordings of head-fixed cats or rats have shown that many neurons in this area are active during REM sleep and/or wakefulness (Steriade et al., 1990; Thakkar et al., 1998; Boucetta and Jones, 2009; Boucetta et al., 2014). A recent study in transgenic mice showed that optogenetic stimulation of cholinergic PPT and LDT neurons increases the probability of entering REM sleep (Van Dort et al., 2015). Together, these studies strongly suggest a role for PPT/ LDT neurons in REM sleep control.

However, given the cellular heterogeneity of the PPT and the fact that previous lesion, electrical stimulation, and drug injection studies likely affected all types of PPT neurons at once, we sought to define the specific contributions of PPT cholinergic, glutamatergic, and GABAergic neurons to the regulation of cortical activity and behavioral state. Based upon prior research, we hypothesized that activation of cholinergic neurons would increase REM sleep, whereas activation of glutamatergic and GABAergic neurons would promote arousal. To test these hypotheses, we used a genetically targeted approach to map the anatomical projections of each neuronal population and to evaluate the effects on sleep/wake behavior of chemogenetic manipulation of each PPT neuron population.

\section{Materials and Methods}

All experimental procedures were performed in accordance with the National Institutes of Health Guidelines, and were approved by the Institutional Animal Care and Use Committee of Beth Israel Deaconess Medical Center.

Animals. We used three different mouse lines in these experiments. To study glutamatergic PPT neurons, we used mice expressing Cre recombinase exclusively in neurons producing the vesicular glutamate transporter-2 (vGluT2-Cre mice; Vong et al., 2011); to study cholinergic neurons, we used mice expressing Cre only in neurons producing choline acetyltransferase (ChAT-Cre mice; Rossi et al., 2011); and to study GABAergic neurons, we used mice expressing Cre only in neurons pro- ducing the vesicular GABA transporter ( $v$ GAT-Cre mice; Vong et al., 2011). All three recombinant mouse lines shared a similar design, with IRES-Cre inserted just downstream of the $v G l u T 2$, ChAT, or $v G A T$ genes. Each line was backcrossed to C57BL/6J for $>6$ generations. Mice were 8-10 weeks old, male, and weighed $25-30 \mathrm{~g}$ at the beginning of the behavioral experiments. After surgery, mice were singly housed at an ambient temperature of $22 \pm 1^{\circ} \mathrm{C}$ on a $12: 12 \mathrm{~h}$ light/dark cycle (lights on at 6:00 A.M.) with food and water available ad libitum.

Study design. To chemogenetically activate glutamatergic, cholinergic, or GABAergic PPT neurons, we bilaterally microinjected an AAV coding for the Cre-dependent hM3 DREADD (designer receptors exclusively activated by designer drugs) receptor (Alexander et al., 2009) into the PPT of $v$ GluT2-Cre mice $(n=8)$, ChAT-Cre mice $(n=8)$, and $v$ GAT-Cre mice $(n=8)$. To chemogenetically inhibit the glutamatergic neurons, we bilaterally microinjected an AAV coding for the Cre-dependent hM4 DREADD receptor (Armbruster et al., 2007) in an additional cohort of $v$ GluT2-Cre mice $(n=8)$. We instrumented mice for EEG and electromyogram (EMG) recordings and, 3 weeks later, we administered clozapine- $N$-oxide (CNO, $0.3 \mathrm{mg} / \mathrm{kg}$, i.p., in $0.5 \mathrm{ml}$ of saline; SigmaAldrich, \#C0832-5MG) or saline $(0.5 \mathrm{ml})$ in a randomized cross-over design and recorded EEG, EMG, and video for $24 \mathrm{~h}$. Based on pilot data, we tested the $v G l u T 2$-Cre and ChAT-Cre mouse cohorts during the light period at 8:00 A.M. to determine whether activation of PPT glutamatergic or cholinergic neurons promotes wake or REM sleep. We tested $v G A T$-Cre mice during both light and dark periods (8:00 A.M. and 8:00 P.M.) to assess whether activation of GABAergic PPT neurons alters wakefulness and/or sleep. As our original dose of CNO $(0.3 \mathrm{mg} / \mathrm{kg})$ had only small effects in $v G A T$-Cre mice (discussed below), we retested these mice using a higher dose of $\mathrm{CNO}(1.0 \mathrm{mg} / \mathrm{kg})$. As negative controls, we tested the effects of $\mathrm{CNO}$ and saline in three groups of the same genotypes ( $n=6$ in each group) injected with a control AAV vector (see below). For all mice, we allowed a 3-4 $\mathrm{d}$ washout period after each injection.

To examine the projections of PPT neurons, we used conditional anterograde tracing. We unilaterally microinjected an AAV coding for Credependent ChR2 conjugated to mCherry (AAV-ChR2-mCherry) in $v$ GluT2-Cre mice, ChAT-Cre mice, and $v G A T$-Cre mice $(n=2$ per genotype), and, 6-8 weeks later, we immunostained for mCherry and mapped the anterograde projections of each cell type. We used channelrhodopsin-2 (ChR2) rather than hM3 for tracing as ChR2 is optimized for expression on cell membranes and better labels long projections. Other than containing ChR2, the AAV coding for ChR2 was identical to the AAV coding for hM3 with the same serotype and promoter. Both AAVs labeled the same target regions, but axonal labeling was stronger with AAV-ChR2-mCherry.

Surgery. Surgical procedures and AAV injection methods were identical to those described previously (Kantor et al., 2013). In brief, we anesthetized mice with ketamine/xylazine $(100 / 10 \mathrm{mg} / \mathrm{kg}$, i.p.) and placed them in a stereotaxic frame. In pilot studies, we determined that each Cre line required different volumes and specific serotypes of AAV to achieve comparable transduction rates. Therefore, we injected $15 \mathrm{nl}$ of Cre-dependent AAV8-EF1 $\alpha$-DIO-hM3Dq-mCherry (hereafter named AAV-hM3-mCherry; Krashes et al., 2011) bilaterally into the PPT of $v$ GluT2-Cre mice, $30 \mathrm{nl}$ of the same AAV in $v$ GAT-Cre mice, and $150 \mathrm{nl}$ of AAV10-EF1 $\alpha$-DIO-hM3Dq-mCherry (Anaclet et al., 2014) in ChAT-Cre mice. We injected an additional cohort of $v G l u T 2$ mice with $30 \mathrm{nl}$ of a viral vector coding for the inhibitory hM4 receptor (AAV8-EF1 $\alpha$-DIOhM4Di-mCherry). To control for potential off-target effects of CNO, we injected the same volumes of AAV8-EF1 $\alpha$-DIO-ChR2(H134R)mCherry (for $v$ GluT2-Cre and $v$ GAT-Cre mice) and AAV10-EF1 $\alpha$ DIO-ChR2(H134R)-mCherry (for ChAT-Cre mice; hereafter named AAV-ChR2-mCherry) bilaterally into Cre-expressing mice ( $n=6$ per line) as ChR2 and mCherry do not react to CNO. Last, we performed unilateral injections of ChR2-mCherry AAVs in all three mouse lines ( $n=2$ per line) for tracing studies. Titers for all injected viruses were $>10^{12}$ vector genomes per milliliter. The expression of mCherry was comparable in experimental mice and controls, except that ChAT-Cre mice had strong expression of hM3-mCherry in $20 \pm 5 \%$ of all cholinergic PPT neurons, whereas the control mice had ChR2-mCherry expression in only $5-10 \%$ of neurons. We could not reliably estimate transduction effi- 
ciency in the $v G l u T 2-C r e$ and $v G A T$-Cre mice as in situ hybridization is less sensitive than immunostaining.

After the AAV injections, we implanted all mice with stainless steel EEG recording screws (1.5 mm lateral and $1 \mathrm{~mm}$ anterior to bregma; $1.5 \mathrm{~mm}$ lateral and $3 \mathrm{~mm}$ posterior to bregma). For EMG recordings, we implanted two multistranded stainless steel wires (\#AS131, Cooner Wire) into the neck extensor muscles. All leads were connected to a microstrip board and affixed to the mouse's head with dental cement. We administered meloxicam $(5 \mathrm{mg} / \mathrm{kg}$, i.p.) to each mouse immediately after surgery and $1 \mathrm{~d}$ later.

EEG/EMG recordings and analysis. Two weeks after surgery, mice were acclimated to the recording chamber and EEG/EMG cable for 1 additional week. During recordings, EEG/EMG signals were amplified and filtered (EEG: 0.3-35 Hz; EMG: 100-300 Hz; Grass Amplifier 6SS, Grass Instruments); and digitized at $256 \mathrm{~Hz}$ (VitalRecorder, Kissei Comtec) with simultaneous infrared video recordings. We scored sleep/wake signals in $10 \mathrm{~s}$ epochs semiautomatically using SleepSign (Kissei Comtec) and performed manual corrections as needed.

Additional analyses in vGluT2-Cre mice. Chemogenetic activation of glutamatergic neurons increased wakefulness. To characterize this in detail, we examined three aspects of arousal in four of the eight $v$ GluT2-Cre mice: specific behaviors as determined by scoring of videos; wheel running as a measure of motor activity; and open-field testing as a measure of anxiety.

To quantify behaviors, we scored simultaneous video and EEG/EMG recordings of $v$ GluT2-Cre mice during the 30-150 min period after injection of $\mathrm{CNO}$ or saline. We scored behavior in $10 \mathrm{~s}$ epochs into eight categories: sleeping (behaviorally asleep with EEG/EMG showing sleep), exploring (actively moving around the cage), nest building (manipulating the nesting material), quiet wake (EEG/EMG signals consistent with wake but no locomotion), grooming, feeding, drinking, and unknown (uncategorizable behavior).

To quantify locomotor activity in vGluT2-Cre mice, we installed lowtorque, polycarbonate running wheels (Fast-Trac \#K3250, Bio-Serv) in the recording chambers and allowed mice to acclimate to the wheels for 3 weeks before experiments. We recorded wheel rotations in $15 \mathrm{~min}$ intervals using a photodetector under each wheel.

To assess levels of anxiety, we tested $v$ GluT2-Cre mice in an open-field chamber $(50 \times 50 \times 38 \mathrm{~cm}$; Altech Plastics $)$ and analyzed their position and movements within the chamber using video tracking software (AnyMaze, Stoelting). During week 1, mice were acclimated to the openfield chamber in $10 \mathrm{~min}$ sessions on 3 nonconsecutive days to reduce the novelty effect with exposure to the chamber. During week 2, we performed the three 10 min sessions on the same days of the week under three different conditions in a randomized order: $45 \mathrm{~min}$ after saline injection, $\mathrm{CNO}(0.3 \mathrm{mg} / \mathrm{kg})$ injection, or no injection. We analyzed each mouse's core point to map their track and measured total distance traveled, time spent immobile, and time spent in the corners (Brunner et al., 2014; Nguyen et al., 2014).

Additional analyses in ChAT-Cre mice. Activation of cholinergic PPT neurons produced light sleep with frequent transitions between sleep and wakefulness. Light NREM sleep normally occurs during state transitions and accounts for $\sim 5 \%$ of NREM sleep in rats (Bergmann et al., 1987). This state has also been reported with chemogenetic activation of basal forebrain cholinergic neurons in mice (Anaclet et al., 2015; Chen et al., 2016). We operationally defined light NREM sleep as having EEG delta $(0.5-4 \mathrm{~Hz})$ amplitude $<43.5 \%$ of the mean delta amplitude during NREM sleep across the $12 \mathrm{~h}$ light period after saline injection; behavior was scored as deep NREM if delta amplitude was above this threshold. Our threshold is based on human scoring during pilot experiments and minimizes the classification error of epochs for both light NREM and deep NREM sleep. In addition, we scored sleep/wake behavior for the ChAT-Cre cohort in $4 \mathrm{~s}$ epochs to capture brief bouts more accurately.

To analyze how light NREM sleep differs from deep NREM sleep, we performed a state-space analysis of the EEG data from ChAT-Cre mice after CNO or saline injection (Gervasoni et al., 2004; Diniz Behn et al., 2010). This method uses the EEG power spectrum to map characteristics of sleep/wake states by plotting each epoch as a single data point in a two-dimensional space. We first performed a feature selection analysis (calculating the Shannon entropy, which measures the amount of infor- mation in each frequency bin) and identified the most informative EEG frequencies using a Matlab script (www.mathworks.com/help/wavelet/ ref/wentropy.html). We retained features in the $0.5-5.5 \mathrm{~Hz}$ range and divided these by the whole frequency range $(0.5-35 \mathrm{~Hz})$ yielding a power ratio (emphasizing the selected features within the entire frequency range), which we used to define the $x$-axis of the two-dimensional state space. Finally, we defined the $y$-axis as the mean power of each epoch in the $0.5-35 \mathrm{~Hz}$ range.

In vitro electrophysiology. For in vitro electrophysiology recordings, we injected AAV-hM3-mCherry (bilateral injections; $100 \mathrm{nl}$ ) into the PPT of $v$ GluT2-Cre mice ( $n=2$; five cells), ChAT-Cre mice ( $n=2$; five cells), and $v G A T$-Cre mice ( $n=4$; six cells). In pilot experiments, we found patch-clamp recordings of PPT neurons very challenging in adult mice as this region is heavily myelinated. Therefore, we injected AAVs in 10-dold mice and performed the slice recordings $11 \mathrm{~d}$ later. This interval was quite adequate to identify PPT neurons expressing mCherry, but levels of hM3-mCherry may not have been as high as in the mice used for behavioral studies, which were tested $>3$ weeks after AAV injection. As negative controls, we injected AAV-ChR2-mCherry into the PPT of $v$ GluT2-Cre ( $n=1$; four cells), ChAT-Cre $(n=1$; four cells), and $v G A T$-Cre ( $n=1$; three cells) mice of the same age.

To prepare brainstem slices for electrophysiological recordings, we anesthetized the mice with isoflurane (5\% in pure oxygen) and transcardially perfused them with ice-cold artificial CSF (aCSF) containing the following (in mM): $100 \mathrm{~N}$-methyl-D-glucamine (NMDG), $2.5 \mathrm{KCl}, 20 \mathrm{HEPES}, 1.24$ $\mathrm{NaH}_{2} \mathrm{PO}_{4}, 30 \mathrm{NaHCO}_{3}, 25$ glucose, 2 thiourea, $5 \mathrm{Na}$-ascorbate, $3 \mathrm{Na}$ pyruvate, $0.5 \mathrm{CaCl}_{2}, 10 \mathrm{MgSO}_{4}$, $\mathrm{pH} 7.3$ with $\mathrm{HCl}$ when carbogenated with $95 \% \mathrm{O}_{2}$ and $5 \% \mathrm{CO}_{2}$. We quickly removed the brains and sectioned them coronally (250 $\mu \mathrm{m}$ thick) in ice-cold NMDG-based aCSF using a vibrating microtome (VT1000S, Leica). Slices containing the PPT were first transferred into NMDG-based aCSF at $35^{\circ} \mathrm{C}$ for $5 \mathrm{~min}$ and then into normal aCSF containing the following (in $\mathrm{mm}$ ): $120 \mathrm{NaCl}, 2.5 \mathrm{KCl}, 10$ glucose, 26 $\mathrm{NaHCO}_{3}, 1.24 \mathrm{NaH}_{2} \mathrm{PO}_{4}, 4 \mathrm{CaCl}_{2}, 1.3 \mathrm{MgCl}_{2}, 2$ thiourea, $1 \mathrm{Na}$-ascorbate, 3 Na-pyruvate, pH 7.4 when carbogenated with $95 \% \mathrm{O}_{2}$ and $5 \% \mathrm{CO}_{2}$, 310-320 mOsm. After $10 \mathrm{~min}$, we transferred the slices to the recording chamber with normal aCSF at room temperature. We guided our recordings using a combination of fluorescence and infrared differential interference contrast video microscopy using a fixed-stage upright microscope (BX51WI, Olympus America) equipped with a Nomarski water-immersion objective (40× magnification, 0.8 numerical aperture) and IR-sensitive CCD camera (ORCA-ER, Hamamatsu) with images displayed on a computer screen in real time using AxioVision software (Carl Zeiss MicroImaging). We recorded in whole-cell current-clamp configuration using a Multiclamp 700B amplifier (Molecular Devices), a Digidata 1322A interface, and Clampex 9.0 software (Molecular Devices). We used a pipette solution containing the following (in mM): $120 \mathrm{~K}$-gluconate, $10 \mathrm{KCl}, 3 \mathrm{MgCl}_{2}, 10 \mathrm{HEPES}, 2.5 \mathrm{~K}$ ATP, $0.5 \mathrm{Na}$-GTP (pH adjusted to 7.2 with $\mathrm{KOH}, 280 \mathrm{mOsm}$ ). As an objective endpoint, we analyzed the difference in resting membrane potential (between spikes; control: 3-5 min before CNO; CNO: last 2 min of $\mathrm{CNO}$ application). CNO (5 $\mu \mathrm{M})$ did not elicit membrane depolarization in the $v G A T$ neurons, so we tested neurons with a higher dose of CNO $(15 \mu \mathrm{M})$, which also failed to depolarize the membrane at the cell body level.

Immunohistochemistry. After sleep recordings, we injected each mouse with either CNO $(0.3 \mathrm{mg} / \mathrm{kg})$ or saline and $90 \mathrm{~min}$ later intracardially perfused them with PBS and 10\% formalin under deep anesthesia with ketamine/xylazine $(150 / 15 \mathrm{mg} / \mathrm{kg}$, i.p.). We removed the brains and stored them overnight in $10 \%$ formalin at $4^{\circ} \mathrm{C}$. After cryoprotection in a $30 \%$ sucrose solution for another $24 \mathrm{~h}$ at $4^{\circ} \mathrm{C}$, we sectioned brains at $30 \mu \mathrm{m}$ into three series using a sliding microtome (Microm HM 440E, GMI) with the blade cleaned with RNAseZap (Life Technologies) and collected the sections into $1 \%$ formalin in DEPC-PBS.

To establish that AAV injections were centered on the PPT, we mapped the distribution of mCherry-expressing neurons in one series of sections immunolabeled for ChAT. We defined the PPT by the boundaries of the cholinergic population (Saper and Loewy, 1982; Armstrong et al., 1983; Rye et al., 1987).

Immunostaining steps, such as those including PBS washes, were performed as described previously (Burgess et al., 2013). In brief, we placed brain sections in $0.3 \%$ hydrogen peroxide for $30 \mathrm{~min}$ and incubated them 

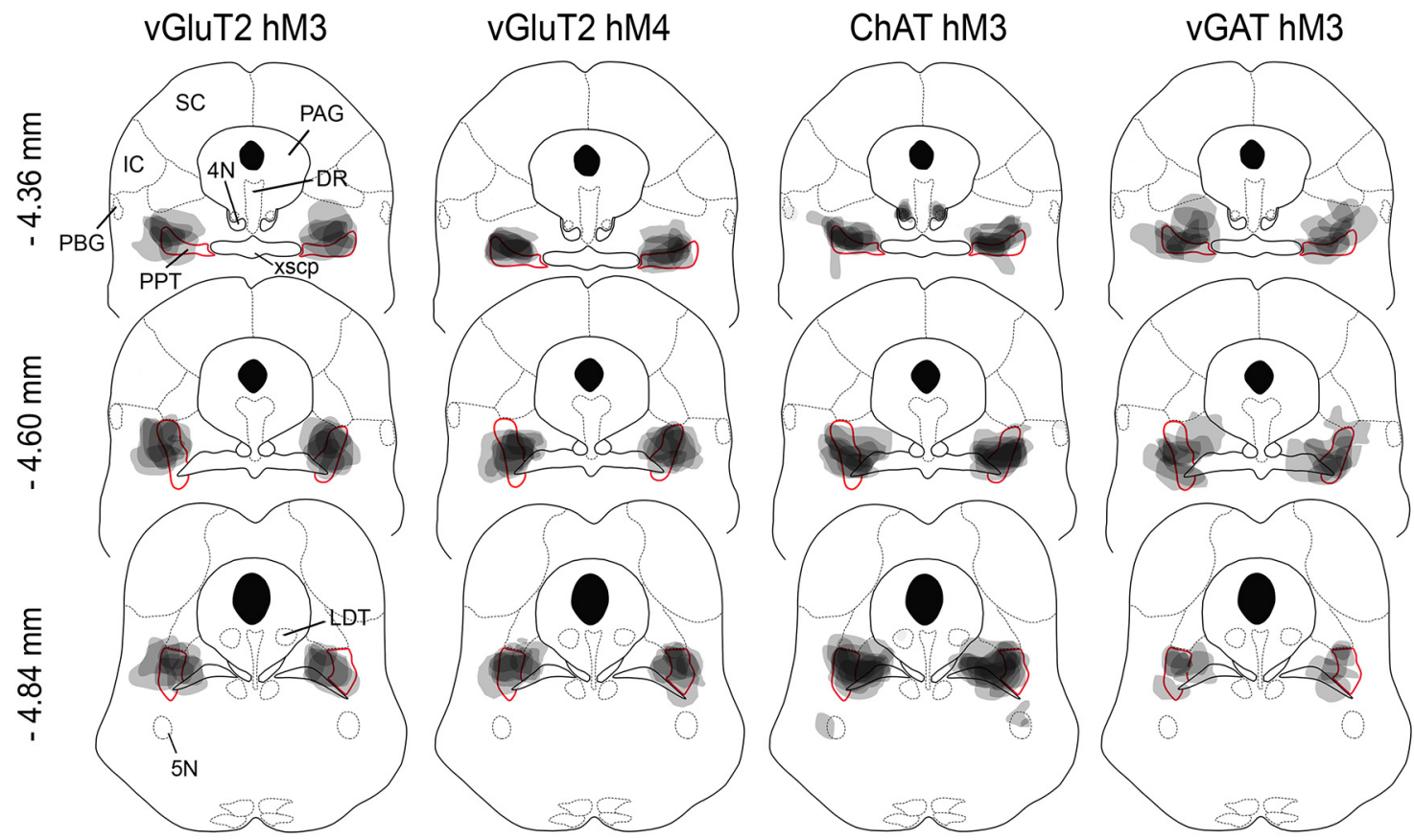

Figure 1. AAV injection sites in VGIuT2-Cre, ChAT-Cre, and vGAT-Cre mice. Injections were mapped on coronal atlas drawings at three brainstem levels containing the PPT. Injection sites (gray shading) are plotted to encompass $90 \%$ of mCherry-expressing neurons, and darker shades of gray represent overlapping injection sites across mice. The red boundary highlights the PPT as shown in the Franklin and Paxinos (2008) mouse brain atlas, but the cholinergic PPT neurons actually extend across a larger region, as shown in VanderHorst and Ulfhake (2006). N = 8 mice per group. SC, Superior colliculus; IC, inferior colliculus; PAG, periaqueductal gray; DR, dorsal raphe nucleus; PBG, parabigeminal nucleus; xscp, decussation of the superior cerebellar peduncle; $4 \mathrm{~N}$, trochlear nucleus; $5 \mathrm{~N}$ trigeminal motor nucleus.

overnight in goat anti-ChAT antiserum (1:750; Millipore, \#AB-144p). The next day, we incubated sections for $1 \mathrm{~h}$ in biotinylated donkey antigoat IgG secondary antiserum (1:500; Jackson ImmunoResearch, \#705065-147) followed by $2 \mathrm{~h}$ of incubation with a streptavidin-conjugated fluorescent antibody (1:1000; Alexa 488, Invitrogen, \#S11224). Using native mCherry fluorescence, we mapped the distribution of mCherryexpressing neurons in relation to the cholinergic neurons of the PPT with a boundary that encompassed $\sim 90 \%$ of all mCherry-containing neurons. Importantly, we found that cholinergic PPT neurons extended slightly outside the boundaries of the PPT shown in the Franklin and Paxinos (2008) mouse brain atlas, but the distribution was quite similar to that depicted by VanderHorst and Ulfhake (2006). In all three groups of mice, the injection sites were centered on the pars compacta of the PPT and extended rostrally into the pars dissipata (Fig. 1). Some vGluT2-Cre and $v G A T$-Cre mice had a small number of mCherry-containing neurons in adjacent regions, such as the retrorubral nucleus, the medial paralemniscal nucleus, and the rostral parabrachial nucleus, as well as in the isthmic reticular formation. Of the eight ChAT-Cre mice included in the analysis, seven had unilateral mCherry-expressing neurons in the fourth motor nerve nuclei, two showed expression in the parabigeminal nucleus, one mouse had expression in the fifth motor nerve nucleus, and one mouse had expression in the LDT. For all three groups, mice were included in the analysis only if $>70 \%$ of the labeled neurons were within the PPT.

To determine whether a comparable volume of tissue was transduced in each mouse and between cohorts, we measured the area of mCherryexpressing neurons on 13 adjacent sections from one series through the PPT region. We then combined areas across all sections and calculated the total volume of transduced neurons for each mouse using ImageJ (Schneider et al., 2012). In all three lines of mice, the rostral-caudal distribution of transduced neurons was similar, and the total volume of transduced neurons did not differ between groups ( $v$ GluT2: $0.36 \pm 0.06$ $\mathrm{mm}^{3}$; ChAT: $0.44 \pm 0.02 \mathrm{~mm}^{3} ; v G A T: 0.43 \pm 0.09 \mathrm{~mm}^{3} ; F_{(2,21)}=0.47$, $p=0.6$, ANOVA).

Next, we mapped fos expression as a marker of neuronal activity in a second series of sections. We incubated sections overnight at room temperature with a rabbit anti-c-fos antibody (1:5000; Calbiochem, \#IC32).
The next day, we incubated sections with biotinylated donkey anti-rabbit secondary antiserum (1:500; Jackson ImmunoResearch, \#711-065-152) for $1 \mathrm{~h}$, followed by horseradish peroxidase-conjugated avidin-biotin complex (1:1000; Vector Labs, \#PK-6100) for $1 \mathrm{~h}$. We visualized fos immunoreactivity using $0.06 \%$ DAB solution with $0.01 \%$ hydrogen peroxide, $0.01 \%$ nickel ammonium sulfate, and $0.005 \%$ cobalt chloride, resulting in black nuclear labeling. We then incubated sections in rabbit anti-DsRed primary antibody, which labels mCherry (1:500; Clontech, \#632496), followed by the same biotinylated donkey anti-rabbit secondary antiserum and $\mathrm{DAB}$ without nickel and cobalt to produce brown labeling of mCherry-expressing neurons. We then digitized sections using a slide-scanning microscope (VS120, Olympus). We defined the boundaries of the PPT using adjacent sections immunolabeled for ChAT and counted single-labeled and double-labeled neurons within the PPT.

To analyze PPT projection targets, we performed DAB immunostaining on one series of brain slices (two mice per Cre line) using the same protocol and antibodies (rabbit anti-DsRed) as above.

Fluorescence in situ hybridization. We placed one series of sections on a shaker at room temperature in RNAlater cryoprotectant solution (Ambion) for $1 \mathrm{~h}$ and then stored them overnight at $-20^{\circ} \mathrm{C}$. In preparation for the hybridization step, we rinsed the sections four times in DEPC-PBS for $5 \mathrm{~min}$ per wash and then incubated the sections in hybridization buffer [50\% formamide (Fisher), $5 \times$ saline-sodium citrate (SSC) buffer (Promega), $0.5 \mathrm{mg} / \mathrm{ml} \mathrm{t-RNA} \mathrm{(Roche),} \mathrm{5 \%} \mathrm{dextran} \mathrm{(Sigma-Aldrich),} 1 \times$ Denhardt's solution (Sigma-Aldrich), 0.1\% Tween 20 (Sigma-Aldrich), and $\mathrm{DEPC}-\mathrm{H}_{2} \mathrm{O}$ ] for $1 \mathrm{~h}$ at $54^{\circ} \mathrm{C}$.

For vGAT fluorescence in situ hybridization (FISH), we used a digoxigenin-labeled antisense riboprobe corresponding to the first 542 bp of exon 2 of the $v G A T$ gene (NM_009508.2; base pairs 874-1416). We transcribed the sequence from a plasmid (pGEM-T Easy Vector, $3557 \mathrm{bp}$ with insert), linearized it with Sac1 (New England Biolabs), and transcribed the riboprobe using T7 polymerase (Roche) in nucleotide triphosphates with digoxigenin-conjugated UTP (uridine 5 '-triphosphate; Roche). We incubated sections in this riboprobe $(300 \mathrm{ng} / \mu \mathrm{l})$ at $54^{\circ} \mathrm{C}$ overnight. For vGluT2 FISH, we used a 458 bp fragment of the mouse vGluT2 Exon1-4 (NM_080853.3; base pairs 829-1287) from a 

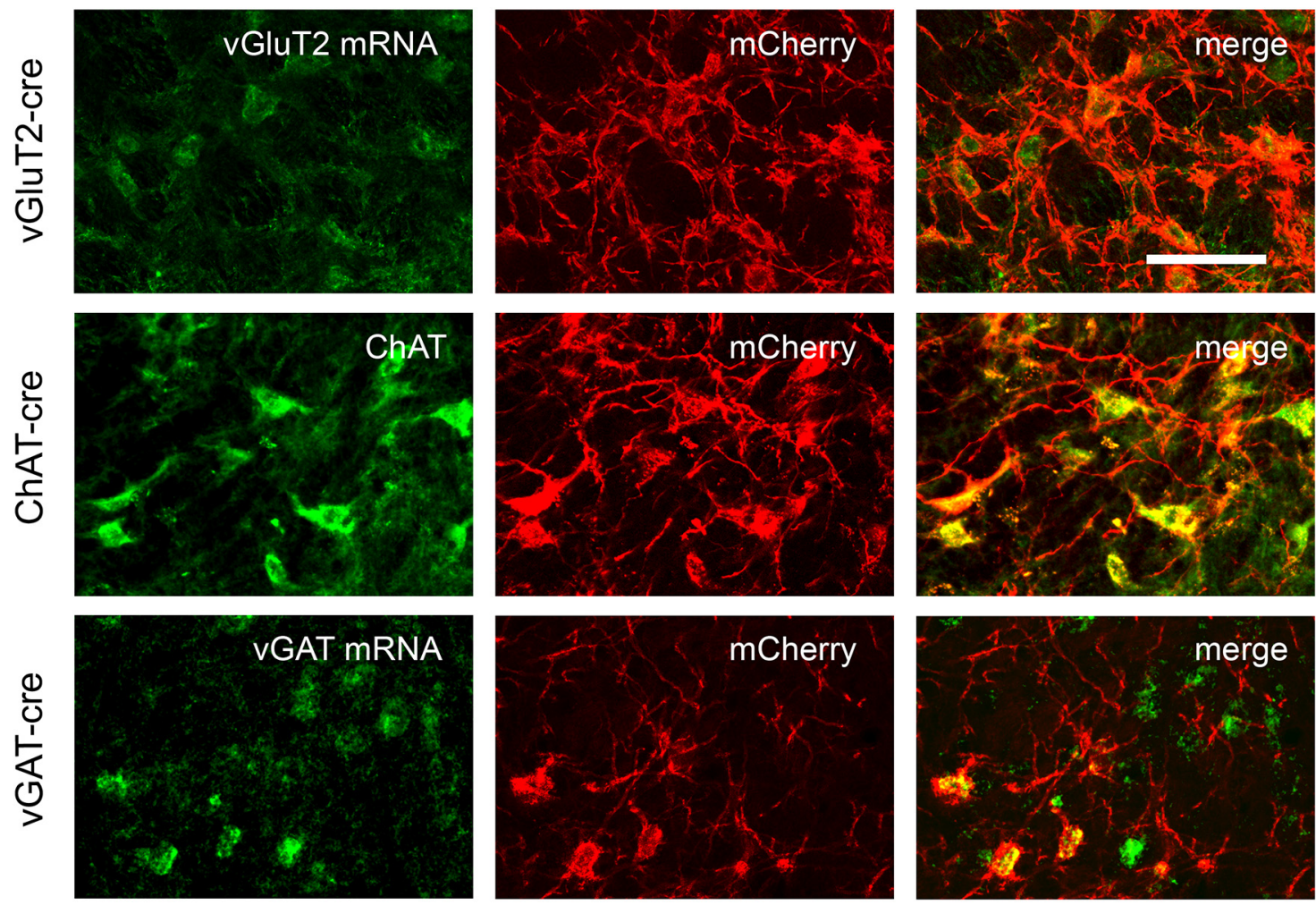

Figure 2. hM3-mCherry is expressed eutopically in vGluT2-Cre, ChAT-Cre, and vGAT-Cre mice. In vGluT2-cre mice, FISH for vGluT2 mRNA colocalizes with mCherry immunostaining. In ChAT-Cre mice, immunostaining for ChAT colocalizes with mCherry. In vGAT-Cre mice, FISH for vGAT mRNA colocalizes with mCherry. Scale bar, $100 \mu \mathrm{m}$.

plasmid (pGEM-T Easy Vector, 3473 bp with the vGluT2 sequence), which we linearized, transcribed, and hybridized as above.

After hybridization, we washed the sections in $2 \times$ SSC in $50 \%$ formamide for $45 \mathrm{~min}$ at $54^{\circ} \mathrm{C}$, followed by two $30 \mathrm{~min}$ washes in $2 \times$ SSC. We then eliminated nonhybridized riboprobe by washing sections twice for $5 \mathrm{~min}$ at room temperature in RNase buffer $(0.5 \mathrm{M} \mathrm{NaCl}$ and $10 \mathrm{~mm}$ Tris- $\mathrm{HCl}$ ) before and after a $30 \mathrm{~min}$ incubation at $37^{\circ} \mathrm{C}$ in RNase A $(50 \mu \mathrm{g} / \mathrm{ml})$. Again, we washed the sections in $2 \times$ SSC $(5 \mathrm{~min}$ at room temperature), then two washes in SSC-50\% formamide $\left(5 \mathrm{~min}\right.$ at $\left.54^{\circ} \mathrm{C}\right)$, followed by two washes in SSC-50\% formamide in DEPC- $\mathrm{H}_{2} \mathrm{O}(5 \mathrm{~min}$ at room temperature), and three washes in TBS (5 min at room temperature). Afterward, we incubated the sections in Blocking Reagent (PerkinElmer, \#FP1019), diluted to 5\% w/v in TBS with $0.1 \%$ Tween at $54^{\circ} \mathrm{C}$ ) for $30 \mathrm{~min}$ and then added anti-digoxigenin peroxidase, Fab fragments (Roche, \#11-207-733-910) to this blocking solution at a 1:200 dilution for overnight incubation at room temperature.

To label the riboprobes, we washed sections three times in TBS for 10 min before starting the fluorescence tyramide signal amplification. For this, we incubated the sections for $30 \mathrm{~min}$ at room temperature in biotinylated tyramide solution (PerkinElmer, \#FP1019) diluted 1:50 in \#FP1050 solution followed by washes in TBS for $5 \mathrm{~min}$ ), in PBS for 1 min rinse, again in PBS for $10 \mathrm{~min}$, and then in PBS containing 0.3\% Triton X-100, v/v (PBT), for $2 \mathrm{~h}$, followed by incubation in streptavidinAlexa 488 (1:1000; Invitrogen, \#S11223) in PBT for $2 \mathrm{~h}$ at room temperature. After three further $5 \mathrm{~min}$ washes in PBS, we immunolabeled sections for DsRed as described above because the FISH protocol eliminated the native red fluorescence.

Validation of neurochemical specificity. We determined the neurochemical phenotype of hM3-expressing neurons by processing them for FISH (for vGluT2 or vGAT) or immunolabeling them for ChAT $(n=2$ mice in each group; three sections per mouse). In addition to the specific labeling for each cohort's genotype ( $v G l u T 2 / v G A T / C h A T)$ in green fluorescence, we also immunolabeled the same sections for mCherry with red fluorescence to highlight transduced neurons. To estimate specificity of mCherry expression, we counted all mCherry-labeled neurons within the PPT and assessed whether they were also labeled for vGluT2, vGAT, or ChAT. For $v G l u T 2$ and $v G A T$ mice, we defined the boundaries of the PPT using adjacent sections immunolabeled for ChAT. Expression of mCherry was highly eutopic in all three lines of mice: 93\% (116 of 125 neurons), 91\% (150 of 165 neurons), and 92\% (120 of 130 neurons) of mCherry-expressing PPT neurons contained vGluT2 mRNA, vGAT mRNA, or ChAT in $v G l u T 2-C r e, v G A T$-Cre, and ChAT-Cre mice, respectively (Fig. 2).

Statistical analysis. We performed statistical analyses using STATA (STATA). For comparisons of sleep/wake patterns, we performed paired, two-tailed $t$ tests comparing the $6 \mathrm{~h}$ average amounts of each state after either saline or $\mathrm{CNO}$ injection. If this test yielded a significant difference, we performed a repeated-measures ANOVA on the hourly state amounts for the $6 \mathrm{~h}$ after injections, followed by post hoc, paired, two-tailed Student's $t$ tests per hour when appropriate. For EEG spectra across the $2 \mathrm{~h}$ after injections, we performed an initial ANOVA over the entire spectrum $(0-35 \mathrm{~Hz})$, followed by post hoc, paired, two-tailed $t$ tests on individual frequencies if the ANOVA was significant. For comparisons of in vitro neuronal depolarization, firing frequency, video behavioral scoring, and open-field data, we used paired two-tailed $t$ tests. For within-subject comparisons of non-normally distributed data, such as the analysis of running-wheel behavior, we used the Wilcoxon sign-rank test. Group data in the figures are shown as means \pm SEMs.

\section{Results}

\section{Projections of glutamatergic PPT neurons}

To map the projections of glutamatergic PPT neurons, we microinjected AAV-ChR2-mCherry into the PPT and immunostained sections for mCherry. Similar to prior studies using nonselective conventional tracers (Charara et al., 1996; Martinez-Gonzalez et al., 2011), we found that glutamatergic PPT neurons strongly innervated the caudal basal forebrain [substantia innominata area (SI) and horizontal diagonal band of Broca (HDB)] and the ventral part of the bed nucleus of stria terminalis. These cells also mildly innervated the lateral hypothalamus ( $\mathrm{LH})$, supramammillary area (SUM), and zona incerta, as well as the caudal part of the 


\section{vGluT2}
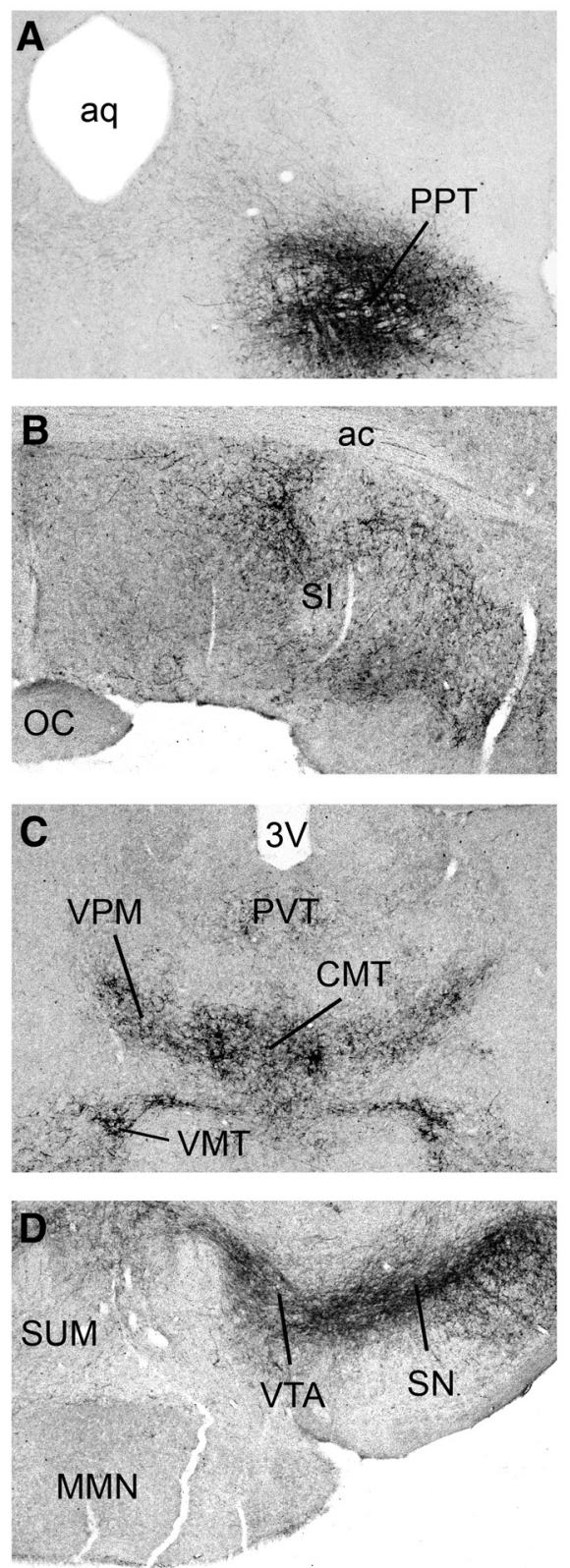

ChAT
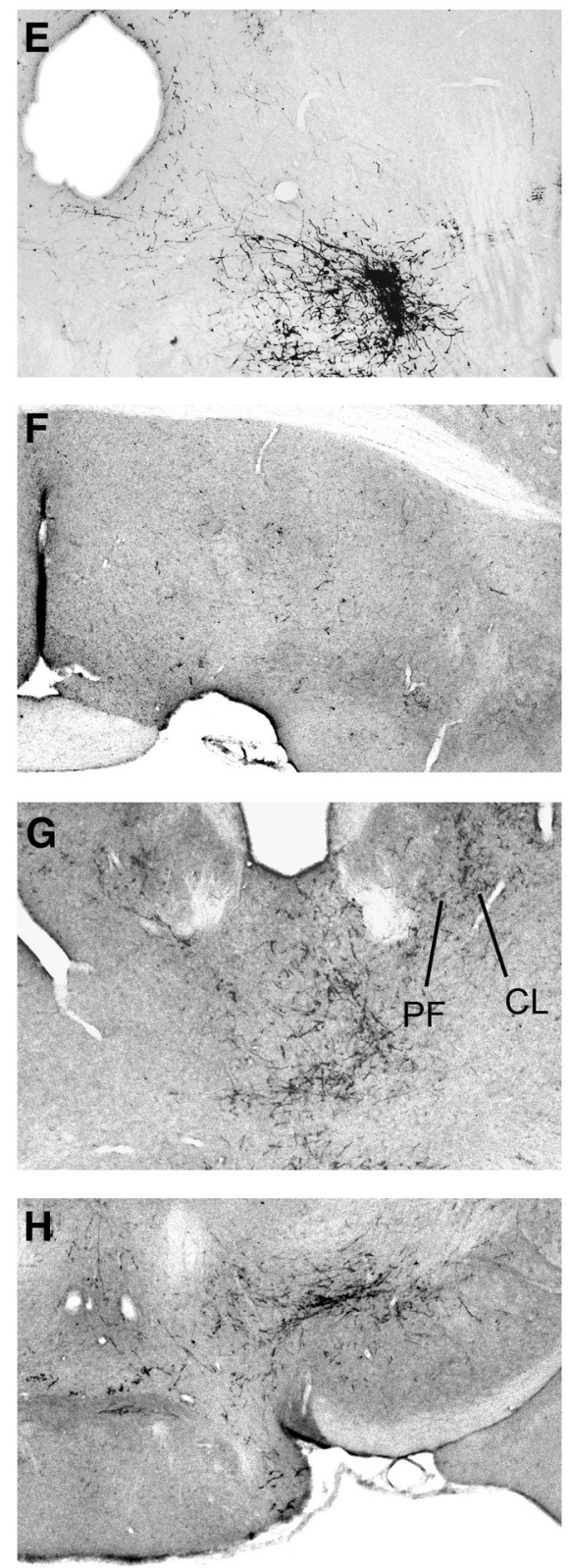

vGAT
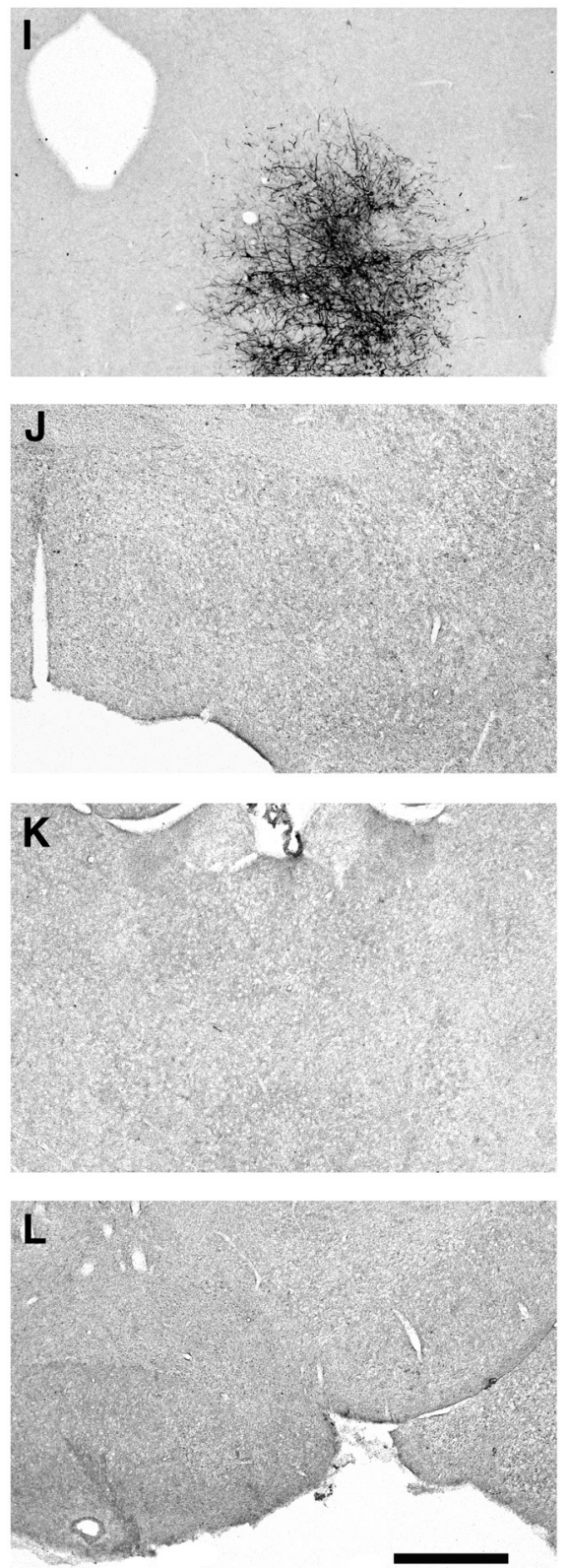

Figure 3. Major axonal projections of glutamatergic, cholinergic and GABAergic PPT neurons. $A-L$, , Projections of each cell type were mapped and selected levels are shown on coronal slices: Injection site $(\boldsymbol{A}, \boldsymbol{E}$, and $\boldsymbol{I})$, basal forebrain area $(\boldsymbol{B}, \boldsymbol{F}$, and $\boldsymbol{J})$, midthalamic area $(\boldsymbol{C}, \boldsymbol{G}$, and $\boldsymbol{K})$, and mammillary region $(\boldsymbol{D}, \boldsymbol{H}$, and $\boldsymbol{L})$. Glutamatergic PPT neurons project densely to basal forebrain targets such as the $S I(B)$, several thalamic nuclei $(\boldsymbol{C})$, and especially to midbrain dopaminergic cell groups (D). Cholinergic PPT neurons project to some of the same targets that glutamatergic neurons project to, but with less dense projections $(\boldsymbol{E}-\boldsymbol{H})$. GABAergic neurons do not send long projections to these regions and most axons remain within $\sim 200 \mu \mathrm{m}$ of the injection site $(\boldsymbol{I}-\boldsymbol{L})$. $N=2$ mice per group. Scale bar in $L=500 \mu \mathrm{m}$. ac, Anterior commissure; aq, aqueduct; $\mathrm{CL}$, centrolateral thalamic nucleus; $O C$, optic chiasm; MMN, medial mammillary nucleus; PF, parafasicular thalamic nucleus; SUM, supramammillary nucleus; VMT, ventromedial thalamic nucleus; VPM, ventral posteromedial thalamic nucleus.

globus pallidus, and thalamic nuclei [centromedial thalamic nucleus (CMT), paraventricular thalamic nucleus (PVT), ventral posteromedial thalamic nucleus, ventromedial thalamic nucleus, parafascicular nucleus]. Axon terminals from glutamatergic PPT neurons were dense within the subthalamic nucleus (STN), VTA, and SN (compact part and reticular part; Fig. $3 A-D$ ). Many of these target regions are thought to help drive arousal, suggesting that glutamatergic PPT neurons may promote wake.

\section{CNO activates hM3-expressing glutamatergic PPT neurons}

To test whether $\mathrm{CNO}$ activates $\mathrm{hM} 3$-expressing glutamatergic neurons in vivo, we injected AAV-hM3-mCherry into the PPT of
vGluT2-Cre mice and examined fos expression after $\mathrm{CNO}$ or saline. Ninety minutes after injection of $\mathrm{CNO}(0.3 \mathrm{mg} / \mathrm{kg})$ at $9: 30$ A.M., 78\% of hM3-mCherry-expressing neurons in the PPT contained fos (517 of 662 mCherry neurons were fos + ), whereas only $8 \%$ of hM3-mCherry neurons contained fos after saline ( 25 of 305 neurons were fos $+; n=3$ mice in each group, $p=0.0001$; Fig. $4 A$ ).

To assess whether CNO depolarizes glutamatergic PPT neurons, we performed in vitro, patch-clamp recordings of PPT neurons expressing hM3-mCherry. CNO (5 $\mu \mathrm{M})$ depolarized hM3-mCherry-expressing neurons by $3.7 \mathrm{mV}$ compared with $\operatorname{aCSF}(-49.3 \pm 5.5$ vs $-53.0 \pm 5.8 \mathrm{mV}, n=5$ cells, $p=0.038$; Fig. 
A

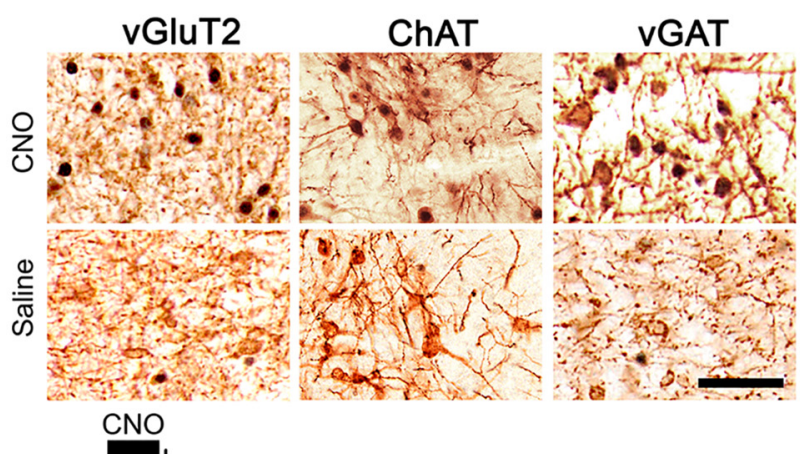

B
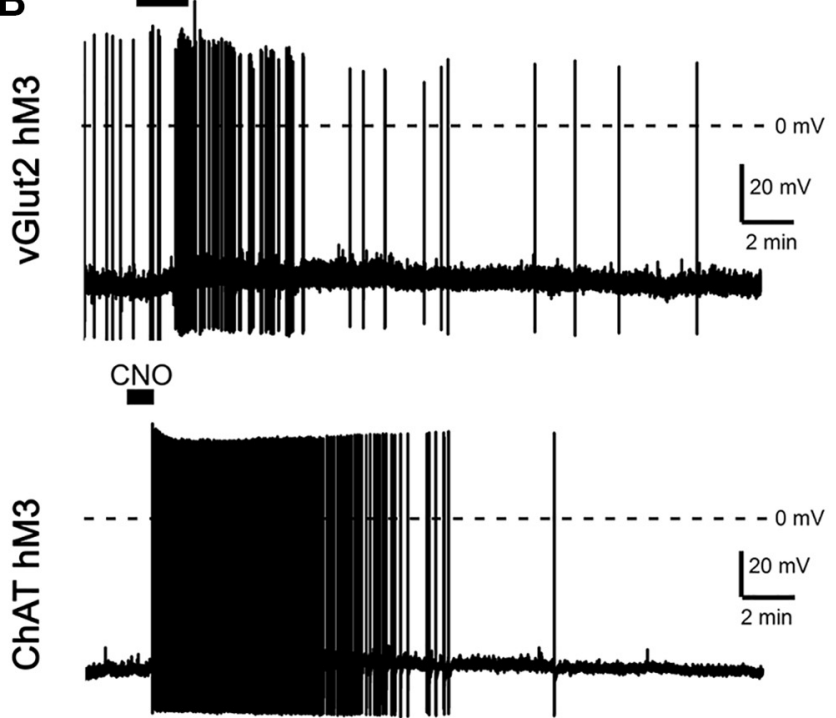
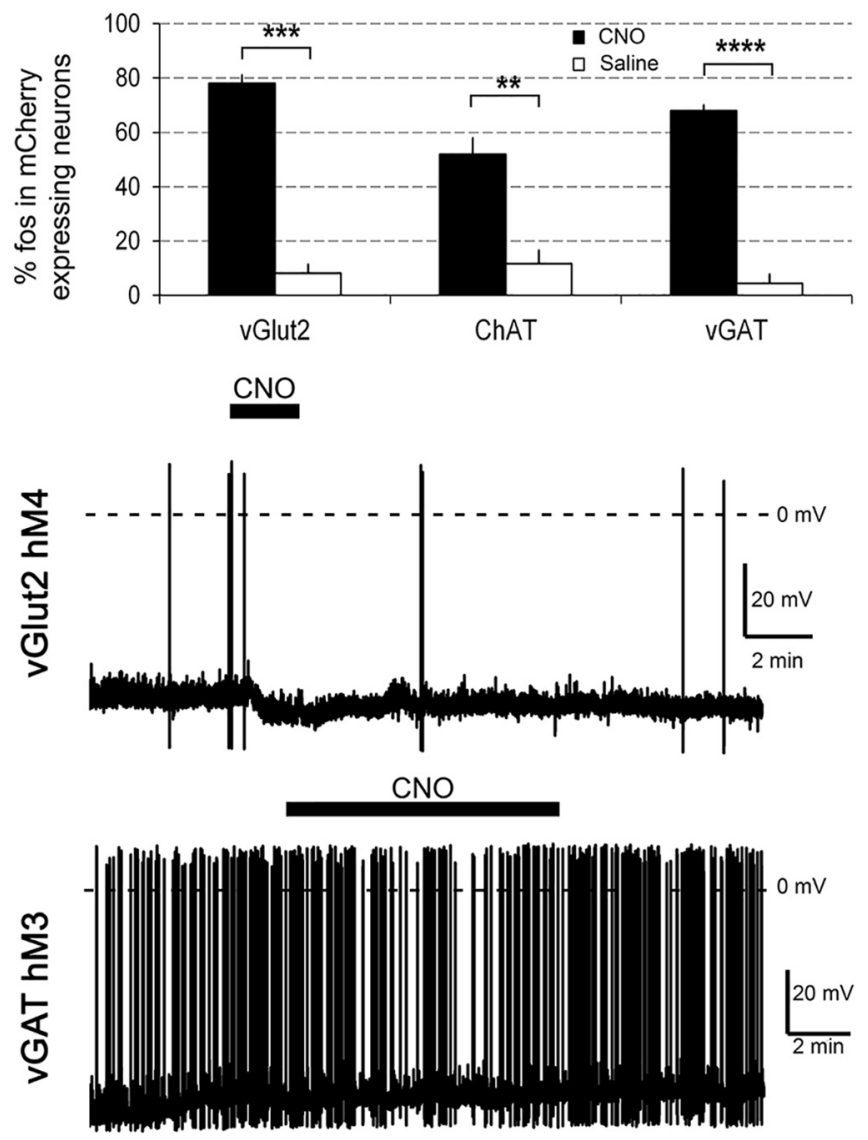

Figure 4. Functional validation of hM 3 in each mouse line. $A, C N O(0.3 \mathrm{mg} / \mathrm{kg}$ ) strongly increases fos in hM3-mCherry-expressing neurons in all three lines of mice compared with saline ( $n=3$ mice of each line per condition). B, Sample traces of in vitro, whole-cell, current-clamp recordings of PPT neurons in vGluT2-Cre, ChAT-Cre, and vGAT-Cre mice expressing hM3-mCherry or hM4-Cherry ( $v$ GluT2-Cre only). Application of CNO (5 $\mu \mathrm{m}$ ) for 1-5 min (black bars above traces) activates glutamatergic and cholinergic PPT neurons but has no effect on GABAergic neurons. Dashed horizontal line indicates $0 \mathrm{mV} .{ }^{* *} p<0.01 ;{ }^{* * *} p<0.001:{ }^{* * *} p<0.0001$ versus saline.

$4 B)$. In $v G l u T 2-C r e$ mice injected with the control vector AAVChR2-mCherry, CNO did not depolarize neurons expressing ChR2-mCherry ( $n=4$ cells). Coupled with the increased expression of fos, these findings indicate that $\mathrm{CNO}$ excites hM3expressing glutamatergic PPT neurons.

\section{Chemoactivation of hM3-expressing glutamatergic PPT neurons increases wakefulness}

To investigate the role of glutamatergic PPT neurons in the regulation of sleep/wake states, we administered CNO or saline to eight $v$ GluT2-Cre mice expressing hM3 in the PPT. Across the $6 \mathrm{~h}$ after injection at 8:00 A.M., CNO $(0.3 \mathrm{mg} / \mathrm{kg})$ increased the average amount of wake $>3$-fold compared with saline (average of $81.5 \pm 5.7 \%$ wake vs $26.2 \pm 1.5 \%, p=0.0001$; Fig. 5). In parallel, CNO reduced the average amounts of both NREM and REM sleep (NREM: $p=0.0001$; REM: $p=0.0001$ ). Similarly, CNO increased the hourly amounts of wake and decreased the amounts of NREM and REM sleep for the first $6 \mathrm{~h}$ after injections (wake: $F_{(1,70)}=88.36, p=0.0001$; NREM: $F_{(1,70)}=76.28, p=$ 0.0001; REM: $\left.F_{(1,70)}=155.91, p=0.0001\right)$. CNO increased the latency to enter the first epoch of sleep $(267.9 \pm 57$ vs $20.1 \pm 5$ min with saline, $p=0.002$ ). The EEG power spectra during $\mathrm{CNO}$-induced wake was very similar to that seen during spontaneous wake during the dark period. Toward the end of the CNOinduced wake period, mice had brief intrusions of EEG delta waves during wake, and then entered typical NREM sleep, which gradually lengthened to the usual duration, with interspersed periods of REM sleep.

To determine whether the observed changes could be a nonspecific effect of $\mathrm{CNO}$, we repeated these experiments with six vGluT2-Cre mice injected with AAV-ChR2-mCherry. These negative control mice had similar expression of mCherry in the PPT, but $\mathrm{CNO}(0.3 \mathrm{mg} / \mathrm{kg})$ did not alter wake or sleep (data not shown). These results suggest that $\mathrm{CNO}$ acts selectively on the $\mathrm{hM} 3$ receptors, and activation of glutamatergic PPT neurons is sufficient to increase wakefulness during the light period.

To characterize the behaviors during arousal induced by $\mathrm{CNO}$, we analyzed home-cage behaviors using video recordings. During the $2 \mathrm{~h}$ after $\mathrm{CNO}$, mice spent most of their time in "quiet wake" in the nest, but this state was uncommon after saline (54 \pm $11 \%$ vs $8 \pm 0.7 \%, n=4, p=0.03$; Fig. $6 A$ ). Compared with spontaneous behavior during the dark period, mice treated with $\mathrm{CNO}$ at 8:00 A.M. exhibited much less time "exploring" ( $p=$ $0.03)$, "feeding" ( $p=0.046)$, and drinking" ( $p=0.01)$, but similar amounts of time "nesting" $(p=0.1)$ and "sleep" $(p=0.37)$.

As prior papers have implicated the PPT in freezing/anxiety (Podhorna and Franklin, 1999; Homs-Ormo et al., 2003) and because mice treated with $\mathrm{CNO}$ had little exploratory activity, we performed open-field testing to assess a possible increase in anxiety. During the light period, $45 \mathrm{~min}$ after $\mathrm{CNO}$, saline, or no injection, we tested mice in an open-field arena $(n=4)$. After $\mathrm{CNO}$, mice spent $58 \%$ more time in the corners compared with 

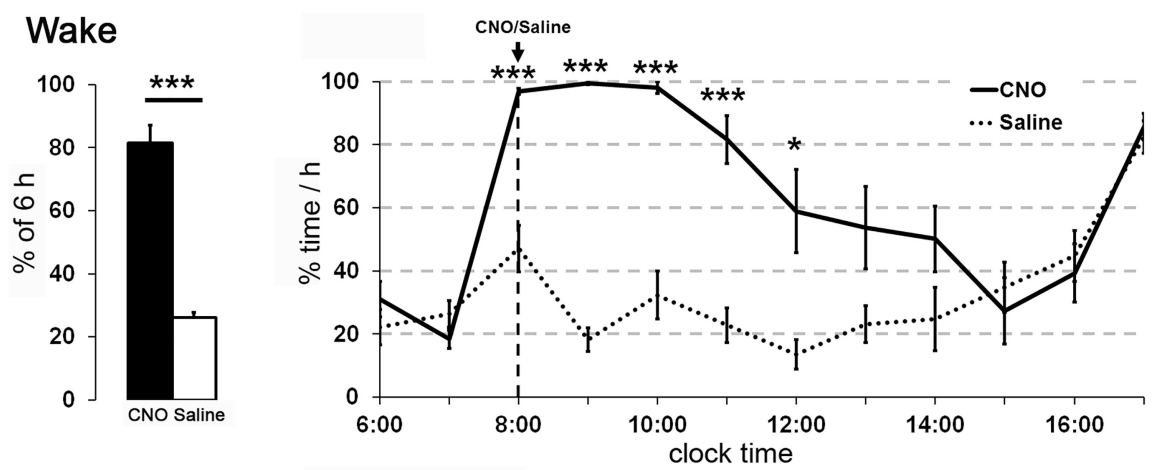

NREM Sleep
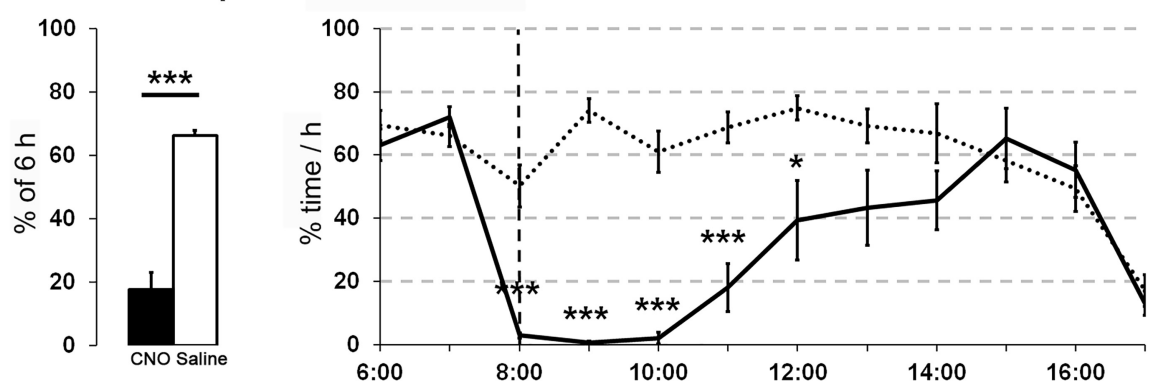

REM Sleep
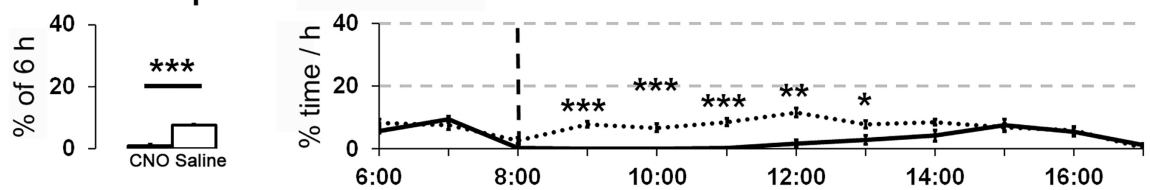

Figure 5. Chemogenetic activation of glutamatergic PPT neurons increases wake. CNO substantially increases wake and reduces NREM and REM sleep for $\sim 7 \mathrm{~h}$ compared with saline ( $n=8 \mathrm{mice})$. CNO $(0.3 \mathrm{mg} / \mathrm{kg})$ and saline were injected intraperitoneally at 8:00 A.M. ${ }^{* *} p<0.01 ;{ }^{* * *} p<0.001$ versus saline.

saline ( $423 \pm 50$ vs $246 \pm 46 \mathrm{~s}, p=0.017$; Fig. $6 B)$. They also tended to spend more time immobile after $\mathrm{CNO}$, but this difference was not significant ( $323 \pm 36$ vs $196 \pm 34 \mathrm{~s}, p=0.1)$. CNO did not alter the total distance traveled ( $29 \pm 8$ vs $34 \pm 4 \mathrm{~m}, p=$ $0.7)$.

To address literature implicating the PPT in motor behaviors and to further characterize the motor phenotype during $\mathrm{CNO}-$ induced wakefulness, we introduced running wheels into the home cages. CNO at 9:00 A.M. increased wheel running 35-fold in the $2 \mathrm{~h}$ immediately after injection compared with saline $(347 \pm 161$ vs $10 \pm 7$ rotations $/ 15 \mathrm{~min}, p=0.01$; Fig. 7$)$. For comparison, this amount of wheel running after $\mathrm{CNO}$ was similar to the amount the mice ran spontaneously at the beginning of the active period from 7:00 P.M. to 9:00 P.M.

Considered together, our behavioral observations demonstrate that chemogenetic activation of glutamatergic PPT neurons produces quiet wake in the unenriched home cage, as well as signs of mild anxiety-like behaviors on open-field testing similar to those described by Brunner and coworkers (Brunner et al., 2014). When mice are given access to running wheels in their home cages, $\mathrm{CNO}$ induces active wakefulness with moderate amounts of wheel running.

Inhibition of hM4-expressing glutamatergic PPT neurons mildly reduces wakefulness during the dark period

To investigate whether CNO inhibits glutamatergic PPT neurons, we performed in vitro patch-clamp recordings of hM4-mCherryexpressing neurons in the PPT region. $\mathrm{CNO}(15 \mu \mathrm{M})$ hyperpolarized
hM4-mCherry-expressing neurons by 3.1 $\mathrm{mV}$ compared with aCSF $(-49.3 \pm 5.5$ vs $-46.3 \pm 4.8 \mathrm{mV}, n=5$ cells, $p=0.01$; Fig. $4 B)$.

To test whether glutamatergic PPT neurons are necessary for wakefulness, we administered $\mathrm{CNO}$ or saline to $8 v G l u T 2-$ Cre mice expressing hM4 in the PPT during the dark period. $\mathrm{CNO}(1.0 \mathrm{mg} / \mathrm{kg})$ at 8 P.M. reduced the average amounts of wake across the $6 \mathrm{~h}$ after injection $(p=$ 0.018 ), and increased NREM sleep ( $p=$ 0.0038 ). CNO did not change the average amounts of REM sleep during this period. Analysis of the hourly changes in sleep/ wake amounts did not show significant changes after $\mathrm{CNO}$ injections compared with saline for the $6 \mathrm{~h}$ after injection (Wake $F_{(1,70)}=4.00, p=0.07$; NREM $F_{(1,70)}=3.78, p=0.07$; REM $F_{(1,70)}=$ $3.00, p=0.1$; Fig. 8). The latency to enter the first epoch of sleep after injections was insignificantly shorter with $\mathrm{CNO}$ compared with saline $(33.2 \pm 4$ vs $73.6 \pm 21$ min, $p=0.06)$. CNO did not alter the EEG power spectra for NREM and REM sleep. These results show that acute inhibition of glutamatergic PPT neurons reduces wake but the effects are modest.

Projections of cholinergic PPT neurons We mapped the projections of cholinergic PPT neurons using AAV-ChR2-mCherry in ChAT-Cre mice, and we found a pattern of projections similar to that reported in rats (Saper and Loewy, 1982; Jones and Yang, 1985; Woolf and Butcher, 1986; Oh et al., 1992; Fig. 3). We found occasional cholinergic PPT axons as far rostral as the medial and lateral septum, with moderate innervation of the SI and HDB, and fewer fibers in the LH. The cholinergic PPT neurons also moderately innervated many thalamic nuclei (PVT; CMT; ventral posteromedial nucleus; centrolateral thalamic nucleus; parafasicular thalamic nucleus; mediodorsal thalamic nucleus, lateral part), with especially strong innervation of the anterior half of the reticular nucleus of the thalamus (RTN) and the anterior pretectal nucleus. Cholinergic innervation was sparse in the STN, VTA, SN (compact and reticular parts), and SUM. The superior colliculus was strongly innervated, and there were scattered fibers in the lateral periaquaeductual gray, but only sparse descending projections to the sublaterodorsal nucleus. Overall, the dense thalamic and especially RTN innervation suggests a role for cholinergic PPT neurons in thalamic activation and arousal.

\section{CNO activates hM3-expressing cholinergic PPT neurons}

To investigate whether $\mathrm{CNO}$ activates hM3-expressing cholinergic neurons in vivo, we examined the expression of fos after $\mathrm{CNO}$ and saline in the PPT of ChAT-Cre mice injected with AAVhM3-mCherry. Ninety minutes after injection of CNO $(0.3 \mathrm{mg} /$ $\mathrm{kg})$ at 9:30 A.M., 52\% of hM3-mCherry-expressing neurons contained fos (279 of 537 mCherry neurons were fos + ), whereas only $12 \%$ contained fos after saline ( 37 of 290 neurons were fos +; $n=3$ in each group, $p=0.006$; Fig. $4 A$ ). 
A
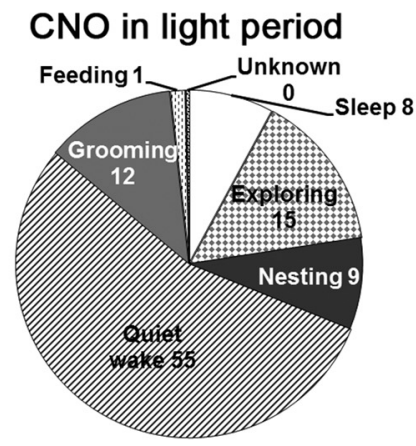

B

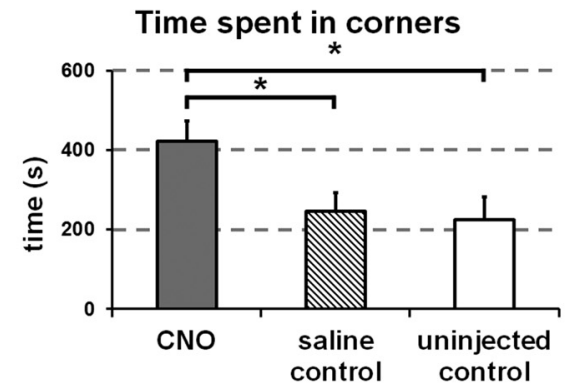

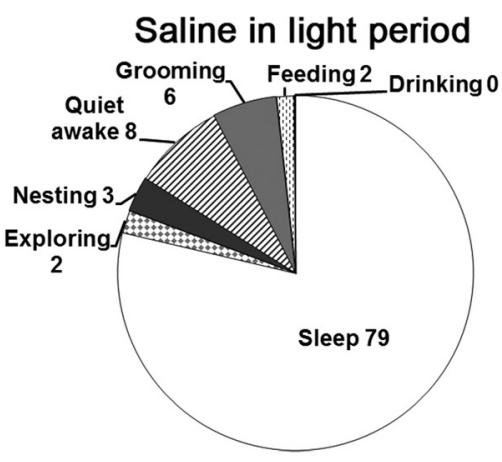

Time spent immobile

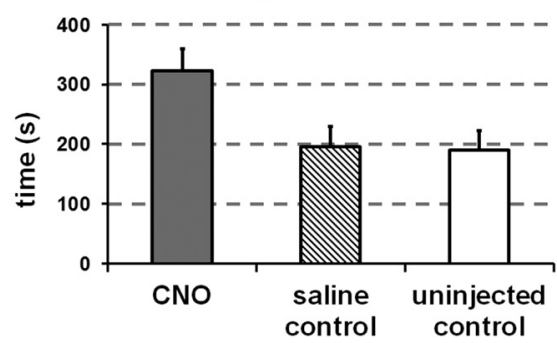

Saline in dark period

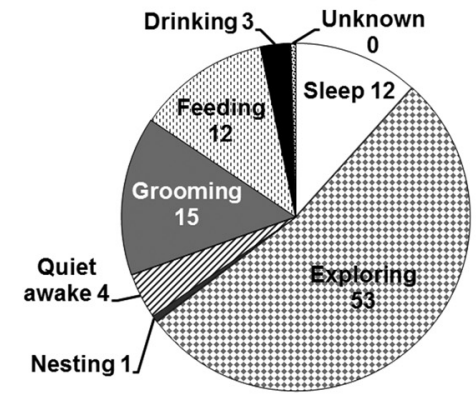

Total distance traveled

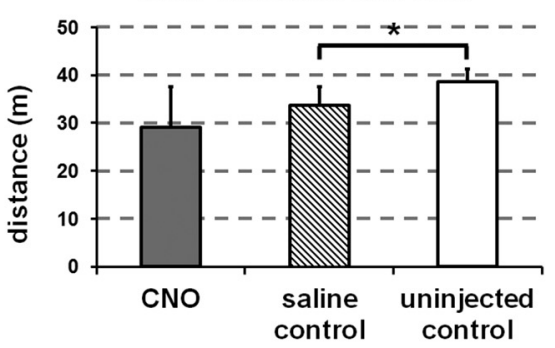

Figure 6. Activation of glutamatergic PPT neurons produces quiet wake and mild anxiety. $A$, After injection of CNO at 8:00 A.M., mice are mainly in quiet wake with modest amounts of time spent exploring, grooming, or nesting from 8:30 A.M. until 10:30 A.M. After injection of saline, mice are mainly asleep with a small amount of time in quiet wake during the same time interval. For comparison to injections in the light period, injections of saline in the dark period at 8:00 P.M. are associated with active wake behaviors, including exploring, grooming, and feeding from 8:30 P.M. until 10:30 P.M. ( $n=4$ mice). $\boldsymbol{B}$, With open-field testing, CN0 increased time in the corners compared with saline or no injection ( $n=4$ mice). ${ }^{*} p<0.05$.

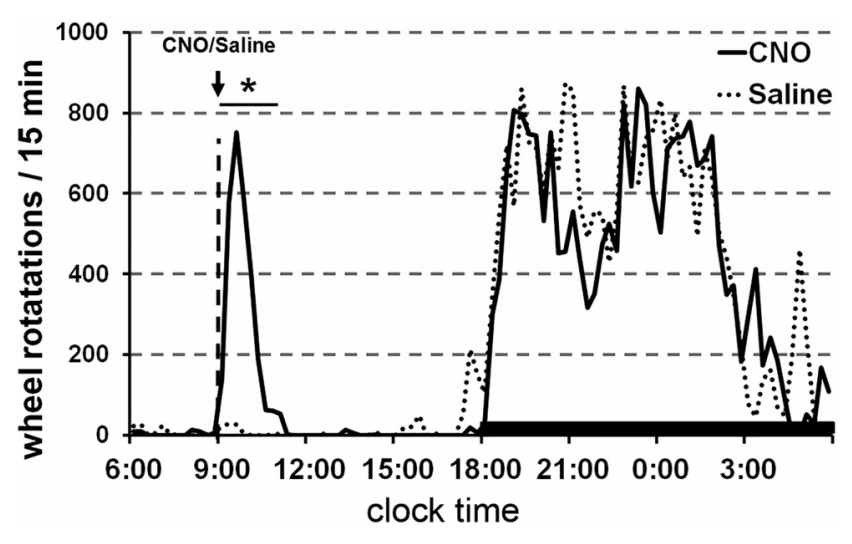

Figure 7. Activation of glutamatergic PPT neurons increases wheel running. CNO administered at 9:00 A.M. increases wheel running for $2 \mathrm{~h}$ to a level similar to that seen during the dark period ( $n=4$ mice). ${ }^{*} p<0.05$ versus saline.

To investigate whether $\mathrm{CNO}$ depolarizes cholinergic PPT neurons, we performed in vitro patch-clamp recordings of hM3mCherry-expressing neurons in the PPT region of ChAT-Cre mice. Bath application of CNO $(5 \mu \mathrm{M})$ depolarized hM3mCherry neurons by $3.7 \mathrm{mV}$ compared with aCSF $(-52.2 \pm 5$ vs $-55.9 \pm 4 \mathrm{mV}, n=5$ cells, $p=0.026$; Fig. $4 B$ ). In ChAT-Cre mice injected with AAV-ChR2-mCherry, CNO did not depolarize neurons expressing ChR2-mCherry $(n=4$ cells). These findings demonstrate that $\mathrm{CNO}$ activates hM3-expressing cholinergic PPT neurons.

Chemoactivation of hM3-expressing cholinergic PPT neurons decreases EEG slow waves during NREM sleep

Activation of PPT cholinergic neurons with CNO did not alter the total sleep/wake amounts, but it markedly reduced EEG slow waves during NREM sleep. After injection of CNO $(0.3 \mathrm{mg} / \mathrm{kg})$ at
8:00 A.M., the total amounts of wake, NREM sleep, and REM sleep did not differ between $\mathrm{CNO}$ and saline conditions (Fig. 9). During NREM and REM sleep, video recordings showed typical sleep behavior with a curled posture and eyes closed. However, spectral analysis of the $2 \mathrm{~h}$ period beginning $30 \mathrm{~min}$ after CNO showed a $41 \pm 5 \%$ reduction in EEG power in the delta and low-theta frequencies $(0-6 \mathrm{~Hz})$ during NREM sleep (Fig. 10). Power around $7 \mathrm{~Hz}$ was unaffected, but intermediate frequencies $(7.5-18.5 \mathrm{~Hz})$ also showed substantial reductions in power $(32 \pm$ $2 \%$ ). The peak EEG frequency during NREM sleep (computed in $0.5 \mathrm{~Hz}$ bins) was similar with $\mathrm{CNO}$ and saline $(3.5$ and $4.0 \mathrm{~Hz}$, respectively).

This NREM sleep with low-delta power resembled a lighter stage of NREM sleep with characteristics similar to the "lowamplitude sleep" described in rats and mice (Bergmann et al., 1987; Anaclet et al., 2015; Chen et al., 2016), leading us to rescore the recordings into "light NREM" and "deep NREM" sleep (see Materials and Methods). In the $6 \mathrm{~h}$ after injection, $\mathrm{CNO}$ increased the average amount of light NREM $>3$-fold compared with saline (average of $11.7 \pm 1 \%$ light NREM vs $3.7 \pm 1 \%, p=$ $0.004)$ and decreased deep NREM sleep to $46.3 \pm 1.8 \%$ compared with $57.6 \pm 1.2 \%$ with saline $(p=0.0009)$. In addition, $\mathrm{CNO}$ increased the hourly amounts of light NREM sleep and decreased the amounts of deep NREM sleep (light NREM: $F_{(1,70)}=32.87$, $p=0.0001$; deep NREM: $\left.F_{(1,70)}=26.58, p=0.0001\right)$, especially in the second and third hours after injection (Fig. 9).

This shift toward light NREM sleep was accompanied by unstable states and more transitions between sleep and wake. During the $2 \mathrm{~h}$ period beginning $30 \mathrm{~min}$ after $\mathrm{CNO} /$ saline, deep NREM bouts were shorter ( $15 \pm 3$ vs $50 \pm 4 \mathrm{~s}, p=0.0001)$ and light NREM bouts were longer ( $7 \pm 1$ vs $4 \pm 0.2 \mathrm{~s}, p=0.002$ ). Wake bouts tended to be shorter ( $30 \pm 5$ vs $43 \pm 6 \mathrm{~s}, p=0.1$ ), while REM bouts were unchanged ( $61 \pm 7$ vs $64 \pm 3 \mathrm{~s}, p=0.7$ ). Overall, CNO-treated mice had approximately twice as many 


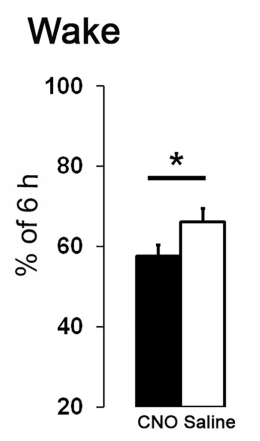

NREM sleep
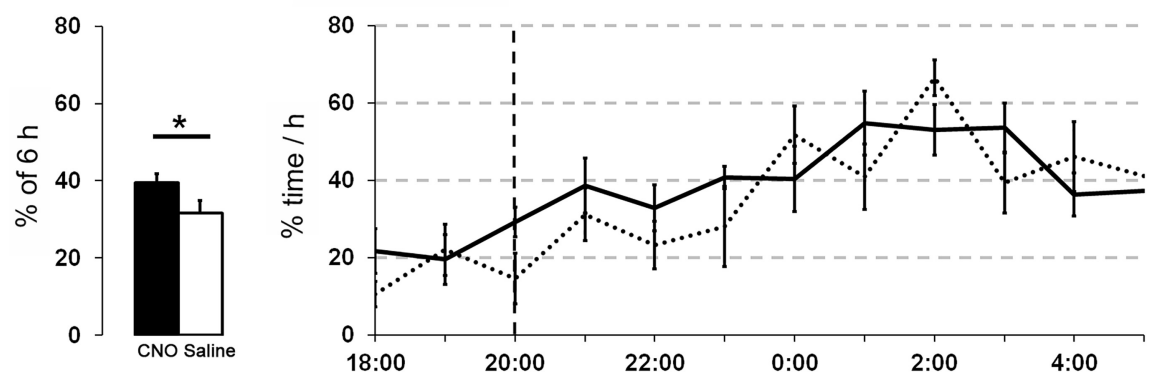

REM sleep
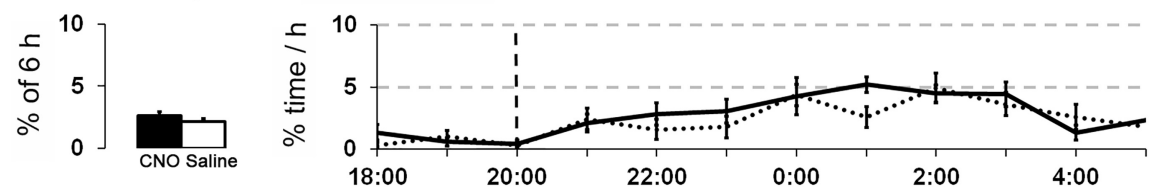

Figure 8. Chemogenetic inhibition of glutamatergic PPT neurons mildly decreases wake and increases NREM sleep. In mice expressing the inhibitory hM4 receptor in vGluT2 PPT neurons, CNO slightly decreased the average amount of wake and increased NREM sleep during the $6 \mathrm{~h}$ after injections ( $n=8$ mice). CNO $(1.0 \mathrm{mg} / \mathrm{kg})$ and saline were injected intraperitoneally at 8:00 P.M. ${ }^{*} p<0.05$.

transitions between all four vigilance states as saline-injected mice $(487 \pm 42$ vs $214 \pm 20, p=0.0004)$ during the $2 \mathrm{~h}$ period 30 min after injection. The seemingly high numbers of transitions even in the saline condition were a consequence of scoring behavior in $4 \mathrm{~s}$ epochs and dividing NREM sleep into two separate states. Activation of cholinergic PPT neurons did not change the latency to the first epoch of NREM sleep (either light or deep NREM sleep) after injection (24.3 \pm 4 vs $25.7 \pm 4 \mathrm{~min}, p=0.8)$.

Using a state-space analysis technique (see Materials and Methods), we compared vigilance states after $\mathrm{CNO}$ and saline. This analysis showed a substantial shift toward light NREM sleep after CNO and a reduction in slow-frequency-rich deep NREM sleep. Moreover, the remaining deep NREM cluster in the CNO condition was markedly reduced in amplitude (Fig. 11).

To test whether CNO nonspecifically affected cortical slow waves, we microinjected AAV-ChR2-mCherry into the PPT of six ChAT-Cre mice. In these negative control mice, CNO $(0.3 \mathrm{mg} /$ $\mathrm{kg}$ ) had no effect on sleep/wake states or EEG spectra compared with saline (data not shown).

Collectively, these findings demonstrate that chemogenetic activation of PPT cholinergic neurons reduces cortical slow waves during NREM sleep and increases transitions between states, but it does not alter the total amounts of sleep and wake.

\section{Projections of GABAergic PPT neurons}

We mapped the efferent projections of the GABAergic PPT neurons using AAV-ChR2-mCherry in $v G A T$-Cre mice. In contrast to prior reports in rats and monkeys (Bevan and Bolam, 1995; Charara et al., 1996), we found that most GABAergic axons remained within the PPT (Fig. 3I-L). A moderate density of axons innervated the caudal part of the retrorubal area immediately lateral to the PPT, but we found no fibers $>200 \mu \mathrm{m}$ from the injection site. This is unlikely to be related to poor anterograde labeling with this vector as the same AAV strongly labeled long projections in the ChAT-Cre and vGluT2-Cre mice.

\section{CNO induces fos in hM3-expressing GABAergic PPT neurons but does not produce obvious depolarization}

We injected AAV-hM3-mCherry into the PPT of $v G A T$-Cre mice and treated them with $\mathrm{CNO}$ or saline. Ninety minutes after injection of CNO $(0.3 \mathrm{mg} / \mathrm{kg})$ at $9: 30$ A.M., $68 \%$ of hM3-mCherry-expressing neurons in the PPT contained fos (571 of 841 mCherry neurons were fos + ), whereas only $4 \%$ expressed fos after saline ( 16 of 361 neurons were fos $+; n=3$ mice in each group, $p=0.0001$; Fig. $4 A$ ).

To test whether CNO depolarizes hM3-expressing vGAT neurons in the PPT, we performed in vitro recordings on brain slices from 21-d-old mice. CNO (5 and $15 \mu \mathrm{M})$ did not significantly change the membrane potential $(-50.6 \pm 2.1$ vs $-51.5 \pm 2.4 \mathrm{mV}, n=6$ cells, $p=0.2)$ or firing frequency $(0.45 \pm 0.1 \mathrm{~Hz}$ pre-CNO vs $0.42 \pm 0.5 \mathrm{~Hz}$ during $\mathrm{CNO} ; p=0.8$; $n=5$ cells) of hM3-mCherry-expressing neurons compared with aCSF (Fig. 4B). In $v G A T$-Cre mice injected with AAV-ChR2mCherry, CNO also did not depolarize neurons expressing ChR2-mCherry ( $n=3$ cells). These results suggest that CNO activates GABAergic PPT neurons enough to induce expression of fos but not enough to produce obvious depolarization.

Chemoactivation of hM3-expressing GABAergic PPT neurons mildly reduces REM sleep and shortens latency to sleep onset To examine the role of GABAergic PPT neurons in sleep/wake modulation, we administered $\mathrm{CNO}$ or saline to eight $v G A T$-Cre mice expressing hM3-mCherry in GABAergic PPT neurons. Injection of CNO $(0.3 \mathrm{mg} / \mathrm{kg})$ early in the light period (8:00 A.M.) did not change the amounts of wake and NREM sleep, but slightly reduced REM sleep (average amounts in the $6 \mathrm{~h}$ after CNO: $5.0 \pm$ $0.3 \%$ vs saline: $6.6 \pm 0.7 \% ; F_{(1,70)}=5.14, p=0.04$; Fig. 12$)$. Latency to enter NREM sleep was shorter after CNO compared with saline $(16.8 \pm 4$ vs $32.8 \pm 4 \mathrm{~min}, p=0.02)$. CNO did not alter EEG spectra during NREM or REM sleep. We also examined the effects of CNO $0.3 \mathrm{mg} / \mathrm{kg}$ in the dark period (8:00 P.M.) but observed no change in sleep/wake behavior $(n=8)$.

As the excitatory effect of hM3 activation can be modest, we repeated the experiments using a higher dose of CNO $(1.0 \mathrm{mg} /$ $\mathrm{kg})$. Across the $6 \mathrm{~h}$ after injection, CNO reduced REM sleep during the light period (CNO: $3.7 \pm 0.6 \%$; saline: $6.0 \pm 0.5 \%, p=$ 0.03 ) and during the dark period (CNO: $1.5 \pm 0.4 \%$; saline: $4.3 \pm$ $0.4 \%, p=0.002)$. 
Collectively, these findings suggest that chemogenetic stimulation of hM3expressing PPT GABAergic neurons is sufficient to induce fos and slightly reduce REM sleep in the light and dark periods. CNO did not depolarize GABAergic PPT neurons, possibly due to technical reasons discussed below.

\section{Discussion}

To investigate the roles of glutamatergic, cholinergic, and GABAergic neurons of the PPT, we examined the efferent projections and chemogenetically manipulated each cell population and evaluated the effects on sleep/wake behavior. We find that chemogenetic stimulation of glutamatergic PPT neurons dramatically increases wakefulness for several hours, with behavior dominated by quiet wakefulness or moderate wheel running. Surprisingly, activation of cholinergic PPT neurons does not affect REM sleep, but instead suppresses slow EEG waves during NREM sleep, producing light and fragmented sleep. Last, stimulation of GABAergic PPT neurons with CNO mildly reduces REM sleep. Overall, these results demonstrate that each neuronal population in the PPT contributes in a distinct and sometimes unexpected way to the control of sleep/ wake behavior and cortical activity.

\section{Functions of glutamatergic \\ PPT neurons}

We find that chemogenetic activation of glutamatergic PPT neurons increases wake for $\sim 7 \mathrm{~h}$ during the light period when mice are normally mostly asleep. Video analysis during this period revealed mainly "quiet wake," whereas "exploring" is the predominant behavior during spontaneous wake during the dark period. One explanation for this quiet behavior after $\mathrm{CNO}$ is that activation of PPT glutamatergic neurons may be sufficient to keep mice awake, but engagement of additional arousal-promoting brain regions is required for a higher level of arousal that spurs exploration and other active behaviors typically seen in the dark period. In addition, circadian signals may promote foraging, feeding, and other goal-directed behaviors during the dark period, but inhibit these behaviors during the light period even if the mouse is awake (Stephan and Zucker, 1972; Chou et al., 2003). The specific pathways through which the glutamatergic neurons promote arousal remain unknown, but the projections to the basal forebrain and LH may promote wake, and the projections to the VTA may promote even higher levels of arousal under motivated conditions, such as the presence of a running wheel (Eban-Rothschild et al., 2016).

In their home cage, mice mainly display "quiet wake" after $\mathrm{CNO}$ activation of glutamatergic PPT neurons, but in an openfield arena, they show signs of mild anxiety, spending more time immobile and in the corner zones of the open field. This is probably not caused by impaired mobility as the total distance traveled
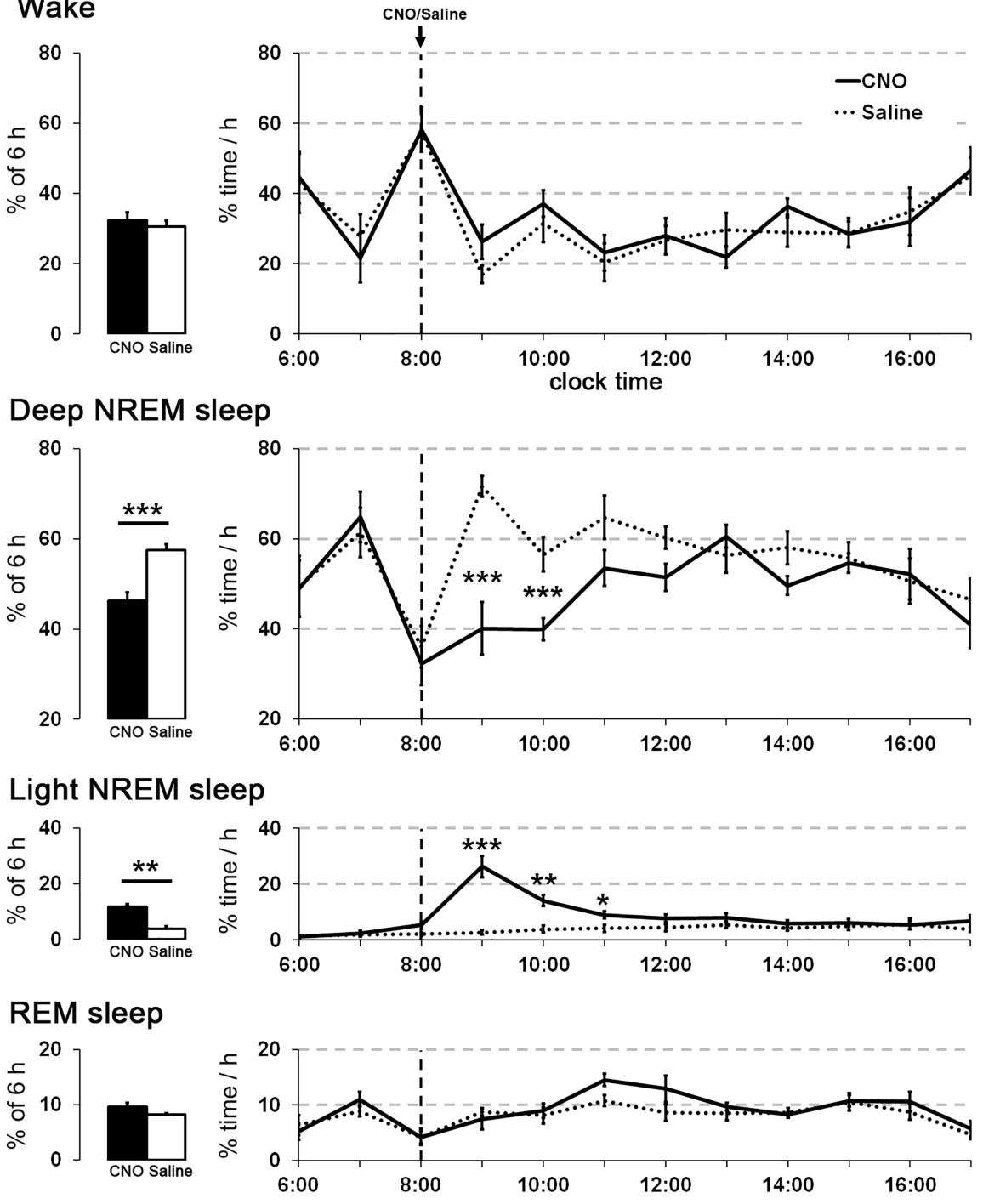

Figure 9. Activation of cholinergic PPT neurons increases light NREM sleep. In ChAT-Cre mice, CNO (0.3 mg/kg) increases light NREM sleep and reduces deep NREM sleep for $\sim 3 \mathrm{~h}$. The amounts of wake and REM sleep are essentially unchanged ( $n=8$ mice). ${ }^{*} p<0.05 ;{ }^{* *} p<0.01 ;{ }^{* * *} p<0.001$ versus saline.

was similar in all three conditions. This apparent increase in anxiety was unexpected as prior studies of PPT-lesioned rats showed no change in anxiety levels in an open-field test (Podhorna and Franklin, 1999; Homs-Ormo et al., 2003). Perhaps, activation of glutamatergic PPT neurons amplified anxiety in the open field simply from a high level of arousal, similar to the apparent increase in anxiety induced by caffeine in rats (Ardais et al., 2014).

Chemogenetic inhibition of glutamatergic PPT neurons with hM4 mildly reduced wakefulness with a concomitant increase in NREM sleep. This modest reduction in wake may reflect redundancy in arousal systems or incomplete inhibition of the glutamatergic PPT neurons.

\section{Functions of cholinergic PPT neurons}

Much research suggests that cholinergic PPT neurons promote REM sleep (Shiromani and McGinty, 1986; Webster and Jones, 1988; Datta et al., 2001; Kubin, 2001; Van Dort et al., 2015), yet we find that activation of cholinergic PPT neurons does not increase REM sleep but instead promotes light NREM sleep. However, our results are not entirely surprising as several other studies raise questions about whether PPT cholinergic signaling is nec- 

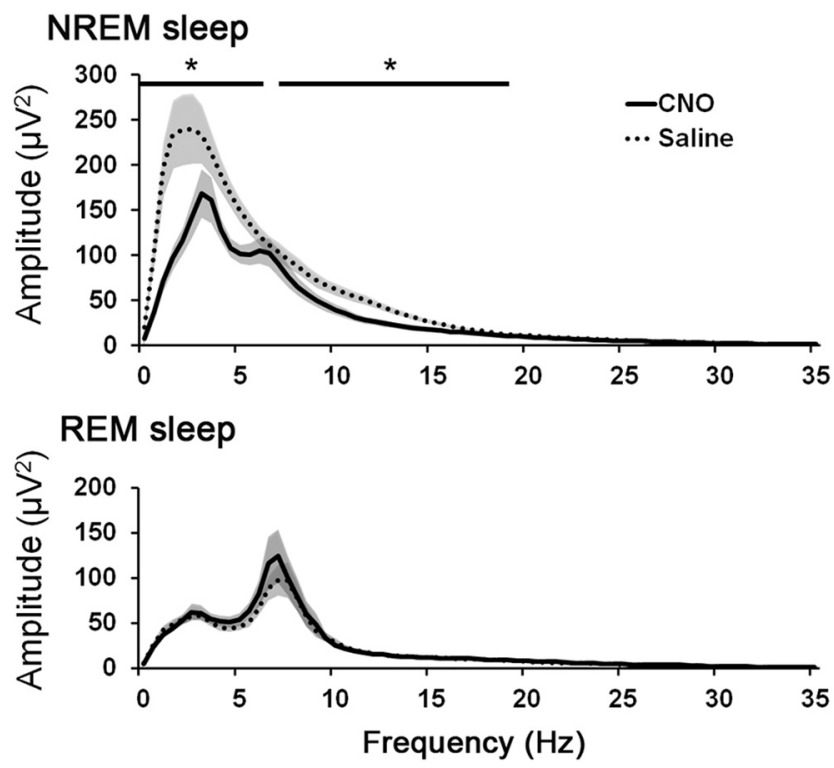

Figure 10. Activation of cholinergic PPT neurons reduces EEG power in the delta range and other slow frequencies during NREM sleep. Administration of $\mathrm{CNO}(0.3 \mathrm{mg} / \mathrm{kg})$ substantially reduces power of low EEG frequencies during NREM sleep, with large reductions in the delta and theta ranges. CNO does not alter the REM sleep EEG spectrum ( $n=4$ mice). ${ }^{*} p<0.05$ versus saline.

essary or even sufficient for the production of REM sleep. For example, focused lesions of the PPT or LDT in rats do not decrease REM sleep (Deurveilher and Hennevin, 2001; Lu et al., 2006) and cholinergic agonists often promote both wake and REM sleep with suppression of slow-wave activity (for review, see Grace and Horner, 2015). Microinjection of a cholinergic antagonist in the sublaterodorsal nucleus decreased hippocampal theta rhythms but otherwise had no effect on REM sleep (Grace et al., 2014). One recent study showed that photostimulation of cholinergic PPT/LDT neurons increases transitions from NREM to REM sleep, but that study used transgenic mice that express ChR2 in all cholinergic neurons; these mice have $>50$ copies of the vesicular acetylcholine transporter $(v A C h T)$ gene, levels of vAChT mRNA $\sim 20$ times higher than normal, and numerous behavioral abnormalities, and they release three times as much acetylcholine as wild-type mice (Kolisnyk et al., 2013). When driven strongly with optogenetics, these mice may release supraphysiological levels of acetylcholine that increase REM sleep and produce other effects that do not occur under typical circumstances. Instead, our results support a model in which physiological cholinergic signaling plays a minor role in generating REM sleep.

We find that chemogenetic activation of cholinergic PPT neurons suppresses slow waves, and this response is very similar to that seen with chemogenetic activation of cholinergic neurons in the basal forebrain (Anaclet et al., 2015; Chen et al., 2016). Chemogenetic activation mildly depolarizes neurons, enabling stronger responses to incoming excitatory stimuli, but the degree of neuronal activation is probably less than that seen with photostimulation; future studies will need to establish which method more closely reflects the natural range of activity. Our findings support the view that by inhibiting slow thalamocortical rhythms, cholinergic PPT neurons enable active brain states, such as wake and REM sleep, but do not drive either state. The pathways through which this occurs are not yet defined, but the cholinergic PPT neurons may suppress slow waves through their
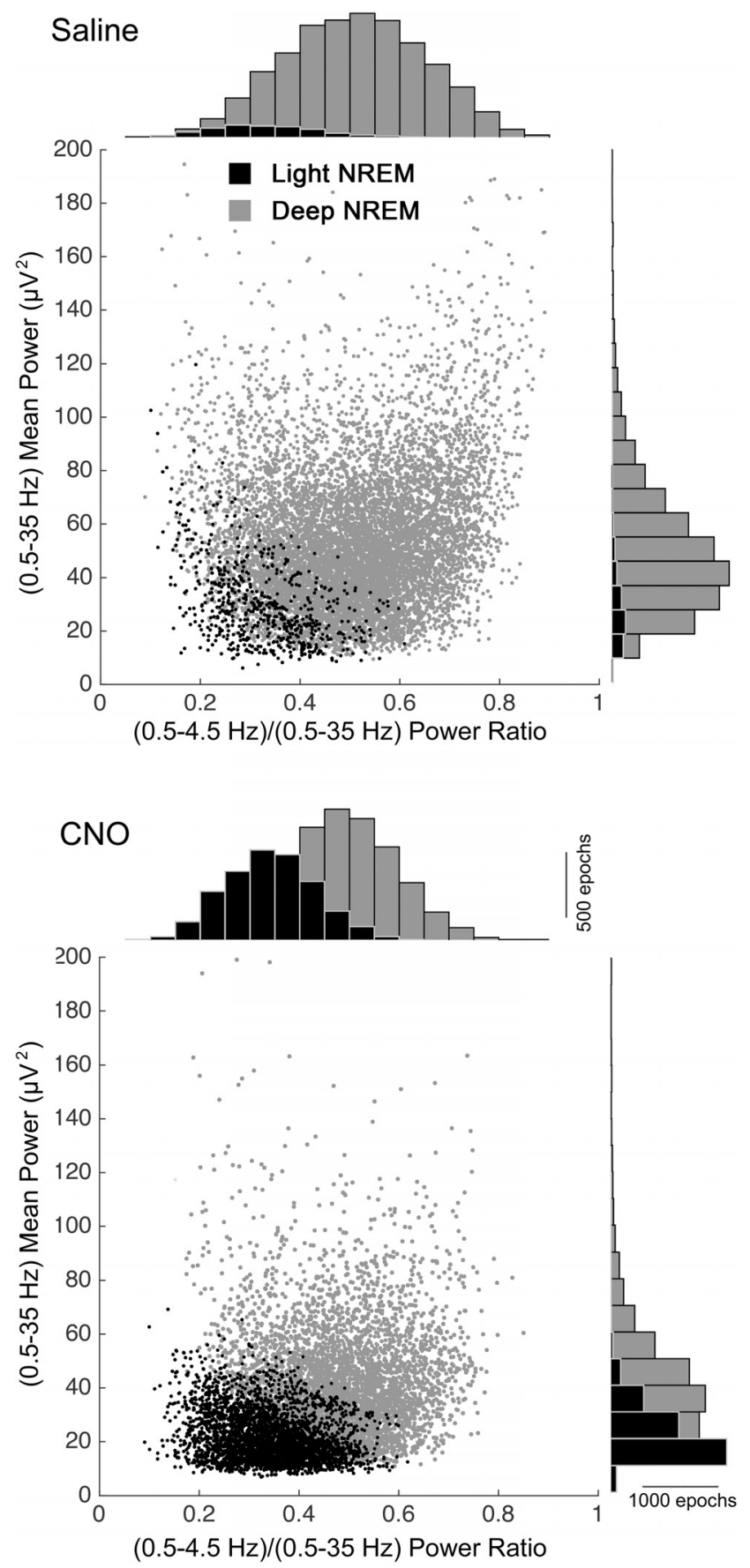

Figure 11. Activation of cholinergic PPT neurons alters state-space characteristics of NREM sleep. Each dot represents EEG spectral characteristics of a 4 s epoch ( $n=8$ mice; see Materials and Methods). CNO reduces the amount of deep NREM sleep (gray dots) and increases the amount of light NREM sleep (black dots). CNO also reduces EEG total power. Histograms on the axes are overlapping.

strong projections to the RTN and other thalamic nuclei (Steriade et al., 1990; Pita-Almenar et al., 2014).

\section{Functions of GABAergic PPT neurons}

While several authors report efferent GABAergic projections from the wider PPT/LDT area (Bevan and Bolam, 1995; Charara et al., 1996), a detailed analysis of only PPT GABAergic neurons concluded that these form almost exclusively local projections (Ford et al., 1995), which meshes well with our observations of just local axons. Juxtacellular unit recordings of identified LDT 
and medial PPT neurons identified two types of GABAergic neurons: one fired maximally during wake and REM sleep, and the other fired maximally just during REM sleep (Boucetta et al., 2014). Moreover, GABAergic PPT/LDT neurons reportedly express fos during rebound REM sleep in rats (Maloney et al., 1999), suggesting a role in REM sleep. We found that chemogenetic activation of the GABAergic PPT neurons mildly reduced REM sleep, so perhaps these neurons are REM sleep active but serve to inhibit REM sleep.

Still, our findings on the effects of hM3 stimulation of GABAergic PPT neurons should be interpreted cautiously. We found that $\mathrm{CNO}$ strongly induced fos in hM3-expressing GABAergic PPT neurons of adult mice, but we did not observe any depolarization of these neurons in PPT brain slices from young mice. Because the PPT is heavily myelinated in adult mice, we performed our electrophysiological recordings in young mice only $11 \mathrm{~d}$ after AAV injections. One possible explanation for the lack of depolarization is that hM3 expression was too low in these young $v G A T$-Cre mice. Alternatively, the hM3 receptors may have been expressed predominantly on vGAT nerve terminals (Mahler et al., 2014), or stimulation by CNO may be enough to induce fos by mobilizing calcium from intracellular stores, but not enough to produce obvious depolarization or GABA release. In the future, this question could be settled with techniques such as photometry to examine the activity of GABAergic PPT neurons in vivo after CNO.

\section{Limitations}

These experiments have a few general limitations. First, our AAV injections induced hM3-mCherry expression in $20 \pm 5 \%$ of PPT ChAT neurons, and vectors with higher transduction efficiency might produce different effects on behavior. We think this is unlikely as activation of even small numbers of neurons is often sufficient to affect behavior; for example, activation of only $25 \%$ of agouti-related peptide neurons in the arcuate nucleus markedly increases feeding (Aponte et al., 2011). Second, accurate microinjections into small brainstem targets are challenging, and our injections often transduced a small number of neurons adjacent to the PPT. However, our AAV injections were centered on the PPT and $\geq 70 \%$ of all transduced neurons lay within the PPT. Third, we focused on the PPT as it is difficult to target the LDT selectively without affecting nearby state-regulatory neurons in the parabrachial nucleus, locus ceruleus, and sublaterodorsal nucleus. Future studies using smaller vector volumes or intersectional genetics may help define the functions of the LDT.

\section{Conclusions}

Overall, these experiments demonstrate that the neuronal populations of the PPT have distinct efferent projections and may differentially influence cortical activity and sleep/wake states.
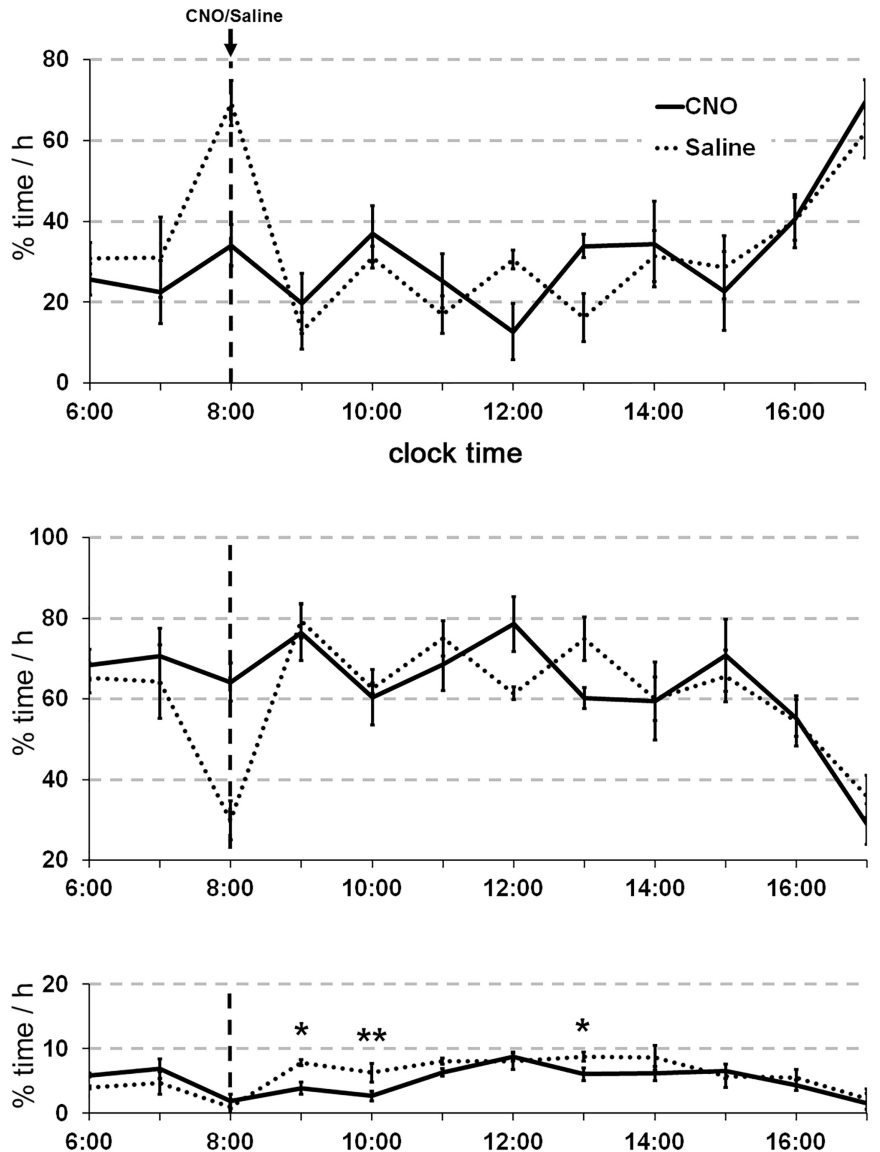

Figure 12. Activation of GABAergic PPT neurons has little effect on sleep/wake behavior. Administration of CNO $(0.3 \mathrm{mg} / \mathrm{kg})$ in $v G A T$-Cre mice during the day does not alter the amounts of wake and NREM sleep, but slightly reduces REM sleep $(n=8$ mice). ${ }^{*} p<0.05 ;{ }^{* *} p<0.01$ versus saline.

Glutamatergic PPT neurons strongly promote wakefulness, cholinergic neurons suppress slow cortical rhythms, and GABAergic neurons slightly reduce REM sleep. Quite possibly, glutamatergic and cholinergic PPT neurons work in concert to produce wakefulness. In future experiments, it will be important to further investigate the nature of wakefulness induced by activation of glutamatergic PPT neurons, and to perform a detailed mapping of the specific inputs to each population of PPT neurons and their projections to brain regions that regulate sleep/wake behavior. Defining the role of specific PPT populations will lead to a better understanding of the mechanisms regulating vigilance states and should ultimately help identify novel targets for the treatment of sleep/wake disorders.

\section{References}

Alexander GM, Rogan SC, Abbas AI, Armbruster BN, Pei Y, Allen JA, Nonneman RJ, Hartmann J, Moy SS, Nicolelis MA, McNamara JO, Roth BL (2009) Remote control of neuronal activity in transgenic mice expressing evolved G protein-coupled receptors. Neuron 63:27-39. CrossRef Medline

Anaclet C, Ferrari L, Arrigoni E, Bass CE, Saper CB, Lu J, Fuller PM (2014) The GABAergic parafacial zone is a medullary slow wave sleep-promoting center. Nat Neurosci 17:1217-1224. CrossRef Medline

Anaclet C, Pedersen NP, Ferrari LL, Venner A, Bass CE, Arrigoni E, Fuller PM (2015) Basal forebrain control of wakefulness and cortical rhythms. Nat Commun 6:8744. CrossRef Medline

Aponte Y, Atasoy D, Sternson SM (2011) AGRP neurons are sufficient to orchestrate feeding behavior rapidly and without training. Nat Neurosci 14:351-355. CrossRef Medline

Ardais AP, Borges MF, Rocha AS, Sallaberry C, Cunha RA, Porciúncula LO 
(2014) Caffeine triggers behavioral and neurochemical alterations in adolescent rats. Neuroscience 270:27-39. CrossRef Medline

Armbruster BN, Li X, Pausch MH, Herlitze S, Roth BL (2007) Evolving the lock to fit the key to create a family of $\mathrm{G}$ protein-coupled receptors potently activated by an inert ligand. Proc Natl Acad Sci U S A 104:51635168. CrossRef Medline

Armstrong DM, Saper CB, Levey AI, Wainer BH, Terry RD (1983) Distribution of cholinergic neurons in rat brain: demonstrated by the immunocytochemical localization of choline acetyltransferase. J Comp Neurol 216:53-68. CrossRef Medline

Baghdoyan HA, Rodrigo-Angulo ML, McCarley RW, Hobson JA (1984) Site-specific enhancement and suppression of desynchronized sleep signs following cholinergic stimulation of three brainstem regions. Brain Res 306:39-52. CrossRef Medline

Bergmann BM, Winter JB, Rosenberg RS, Rechtschaffen A (1987) NREM sleep with low-voltage EEG in the rat. Sleep 10:1-11. Medline

Bevan MD, Bolam JP (1995) Cholinergic, GABAergic, and glutamateenriched inputs from the mesopontine tegmentum to the subthalamic nucleus in the rat. J Neurosci 15:7105-7120. Medline

Boucetta S, Jones BE (2009) Activity profiles of cholinergic and intermingled GABAergic and putative glutamatergic neurons in the pontomesencephalic tegmentum of urethane-anesthetized rats. J Neurosci 29:4664-4674. CrossRef Medline

Boucetta S, Cissé Y, Mainville L, Morales M, Jones BE (2014) Discharge profiles across the sleep-waking cycle of identified cholinergic, GABAergic, and glutamatergic neurons in the pontomesencephalic tegmentum of the rat. J Neurosci 34:4708-4727. CrossRef Medline

Brunner SM, Farzi A, Locker F, Holub BS, Drexel M, Reichmann F, Lang AA, Mayr JA, Vilches JJ, Navarro X, Lang R, Sperk G, Holzer P, Kofler B (2014) GAL3 receptor KO mice exhibit an anxiety-like phenotype. Proc Natl Acad Sci U S A 111:7138-7143. CrossRef Medline

Burgess CR, Oishi Y, Mochizuki T, Peever JH, Scammell TE (2013) Amygdala lesions reduce cataplexy in orexin knock-out mice. J Neurosci 33:9734-9742. CrossRef Medline

Charara A, Smith Y, Parent A (1996) Glutamatergic inputs from the pedunculopontine nucleus to midbrain dopaminergic neurons in primates: phaseolus vulgaris-leucoagglutinin anterograde labeling combined with postembedding glutamate and GABA immunohistochemistry. J Comp Neurol 364:254-266. CrossRef Medline

Chen L, Yin D, Wang TX, Guo W, Dong H, Xu Q, Luo YJ, Cherasse Y, Lazarus M, Qiu ZL, Lu J, Qu WM, Huang ZL (2016) Basal forebrain cholinergic neurons primarily contribute to inhibition of electroencephalogram delta activity, rather than inducing behavioral wakefulness in mice. Neuropsychopharmacology 41:2133-2146. CrossRef Medline

Chou TC, Scammell TE, Gooley JJ, Gaus SE, Saper CB, Lu J (2003) Critical role of dorsomedial hypothalamic nucleus in a wide range of behavioral circadian rhythms. J Neurosci 23:10691-10702. Medline

Datta S, Spoley EE, Patterson EH (2001) Microinjection of glutamate into the pedunculopontine tegmentum induces REM sleep and wakefulness in the rat. Am J Physiol Regul Integr Comp Physiol 280:R752-R759. Medline

Dautan D, Souza AS, Huerta-Ocampo I, Valencia M, Assous M, Witten IB, Deisseroth K, Tepper JM, Bolam JP, Gerdjikov TV, Mena-Segovia J (2016) Segregated cholinergic transmission modulates dopamine neurons integrated in distinct functional circuits. Nat Neurosci 19:10251033. CrossRef Medline

Deurveilher S, Hennevin E (2001) Lesions of the pedunculopontine tegmental nucleus reduce paradoxical sleep (PS) propensity: evidence from a short-term PS deprivation study in rats. Eur J Neurosci 13:1963-1976. CrossRef Medline

Diniz Behn CG, Klerman EB, Mochizuki T, Lin SC, Scammell TE (2010) Abnormal sleep/wake dynamics in orexin knockout mice. Sleep 33:297306. Medline

Eban-Rothschild A, Rothschild G, Giardino WJ, Jones JR, de Lecea L (2016) VTA dopaminergic neurons regulate ethologically relevant sleep-wake behaviors. Nat Neurosci 19:1356-1366. CrossRef Medline

el Mansari M, Sakai K, Jouvet M (1989) Unitary characteristics of presumptive cholinergic tegmental neurons Dduring the sleep-waking cycle in freely moving cats. Exp Brain Res 76:519-529. Medline

Ford B, Holmes CJ, Mainville L, Jones BE (1995) GABAergic neurons in the rat pontomesencephalic tegmentum: codistribution with cholinergic and other tegmental neurons projecting to the posterior lateral hypothalamus. J Comp Neurol 363:177-196. CrossRef Medline
Franklin K, Paxinos G (2008) The mouse brain in stereotaxic coordinates, 3rd ed. Cambridge, MA: Academic.

Gervasoni D, Lin SC, Ribeiro S, Soares ES, Pantoja J, Nicolelis MA L (2004) Global forebrain dynamics predict rat behavioral states and their transitions. J Neurosci 24:11137-11147. CrossRef Medline

Grace KP, Horner RL (2015) Evaluating the evidence surrounding pontine cholinergic involvement in REM sleep generation. Front Neurol 6:190. CrossRef Medline

Grace KP, Vanstone LE, Horner RL (2014) Endogenous cholinergic input to the pontine REM sleep generator is not required for REM sleep to occur. J Neurosci 34:14198-14209. CrossRef Medline

Hallanger AE, Wainer BH (1988) Ascending projections from the pedunculopontine tegmental nucleus and the adjacent mesopontine tegmentum in the rat. J Comp Neurol 274:483-515. Medline

Homs-Ormo S, Coll-Andreu M, Satorra-Marín N, Arévalo-García R, Morgado-Bernal I (2003) Effects of pedunculopontine tegmental nucleus lesions on emotional reactivity and locomotion in rats. Brain Res Bull 59:495-503. CrossRef Medline

Jones BE, Yang TZ (1985) The efferent projections from the reticular formation and the locus coeruleus studied by anterograde and retrograde axonal transport in the rat. J Comp Neurol 242:56-92. CrossRef Medline

Kantor S, Mochizuki T, Lops SN, Ko B, Clain E, Clark E, Yamamoto M, Scammell TE (2013) Orexin gene therapy restores the timing and maintenance of wakefulness in narcoleptic mice. Sleep 36:1129-1138. CrossRef Medline

Kolisnyk B, Guzman MS, Raulic S, Fan J, Magalhães AC, Feng G, Gros R, Prado VF, Prado MA (2013) ChAT-ChR2-EYFP mice have enhanced motor endurance but show deficits in attention and several additional cognitive domains. J Neurosci 33:10427-10438. CrossRef Medline

Krashes MJ, Koda S, Ye C, Rogan SC, Adams AC, Cusher DS, Maratos-Flier E, Roth BL, Lowell BB (2011) Rapid, Reversible Action of AgRP Neurons Drives Feeding Behavior in Mice. J Clin Invest 121:1424-1428. CrossRef Medline

Kubin L (2001) Carbachol Rem models of REM sleep: recent developments and new directions. Arch Ital Biol 139:147-168. Medline

Lu J, Sherman D, Devor M, Saper CB (2006) A putative flip-flop switch for control of REM sleep. Nature 441:589-594. CrossRef Medline

Mahler SV, Vazey EM, Beckley JT, Keistler CR, McGlinchey EM, Kaufling J, Wilson SP, Deisseroth K, Woodward JJ, Aston-Jones G (2014) Designer receptors show role for ventral pallidum input to ventral tegmental area in cocaine seeking. Nat Neurosci 17:577-585. CrossRef Medline

Maloney KJ, Mainville L, Jones BE (1999) Differential c-Fos expression in cholinergic, monoaminergic, and GABAergic cell groups of the pontomesencephalic tegmentum after paradoxical sleep deprivation and recovery. J Neurosci 19:3057-3072. Medline

Martinez-Gonzalez C, Bolam JP, Mena-Segovia J (2011) Topographical organization of the pedunculopontine nucleus. Front Neuroanat 5:22. CrossRef Medline

Mena-Segovia J, Micklem BR, Nair-Roberts RG, Ungless MA, Bolam JP (2009) GABAergic neuron distribution in the pedunculopontine nucleus defines functional subterritories. J Comp Neurol 515:397-408. CrossRef Medline

Nguyen LN, Ma D, Shui G, Wong P, Cazenave-Gassiot A, Zhang X, Wenk MR, Goh EL, Silver DL (2014) Mfsd2a is a transporter for the essential omega-3 fatty acid docosahexaenoic acid. Nature 509:503-506. CrossRef Medline

Oakman SA, Faris PL, Kerr PE, Cozzari C, Hartman BK (1995) Distribution of pontomesencephalic cholinergic neurons projecting to substantia nigra differs significantly from those projecting to ventral tegmental area. J Neurosci 15:5859-5869. Medline

Oh JD, Woolf NJ, Roghani A, Edwards RH, Butcher LL (1992) Cholinergic neurons in the rat central nervous system demonstrated by in situ hybridization of choline acetyltransferase mRNA. Neuroscience 47:807-822. CrossRef Medline

Pita-Almenar JD, Yu D, Lu HC, Beierlein M (2014) Mechanisms underlying desynchronization of cholinergic-evoked thalamic network activity. J Neurosci 34:14463-14474. CrossRef Medline

Podhorna J, Franklin KB (1999) Long-lasting increase in anxiety after electrolytic lesions of the pedunculopontine tegmental nucleus. Behav Neurosci 113:550-557. CrossRef Medline

Rossi J, Balthasar N, Olson D, Scott M, Berglund E, Lee CE, Choi MJ, Lauzon D, Lowell BB, Elmquist JK (2011) Melanocortin-4 receptors expressed 
by cholinergic neurons regulate energy balance and glucose homeostasis. Cell Metab 13:195-204. CrossRef Medline

Rye DB, Saper CB, Lee HJ, Wainer BH (1987) Pedunculopontine tegmental nucleus of the rat: cytoarchitecture, cytochemistry, and some extrapyramidal connections of the mesopontine tegmentum. J Comp Neurol 259: 483-528. CrossRef Medline

Saper CB, Loewy DD (1982) Projections of the pedunculopontine tegmental nucleus in the rat: evidence for additional extrapyramidal circuitry. Brain Res 252:367-372. Medline

Satoh K, Fibiger HC (1986) Cholinergic neurons of the laterodorsal tegmental nucleus: efferent and afferent connections. J Comp Neurol 253: 277-302. CrossRef Medline

Scarnati E, Gasbarri A, Campana E, Pacitti C (1987) The organization of nucleus tegmenti pedunculopontinus neurons projecting to basal ganglia and thalamus: a retrograde fluorescent double labeling study in the rat. Neurosci Lett 79:11-16. CrossRef Medline

Schneider CA, Rasband WS, Eliceiri KW (2012) NIH Image to ImageJ: 25 years of image analysis. Nat Methods 9:671-675. CrossRef Medline

Seigneur J, Kroeger D, Nita DA, Amzica F (2006) Cholinergic action on cortical glial cells in vivo. Cereb Cortex 16:655-668. Medline

Shiromani PJ, McGinty DJ (1986) Pontine neuronal response to local cholinergic infusion: relation to REM sleep. Brain Res 386:20-31. CrossRef Medline

Shiromani PJ, Winston S, McCarley RW (1996) Pontine cholinergic neurons show Fos-like immunoreactivity associated with cholinergically induced REM sleep. Mol Brain Res 38:77-84. CrossRef Medline

Stephan FK, Zucker I (1972) Circadian rhythms in drinking behavior and locomotor activity of rats are eliminated by hypothalamic lesions. Proc Natl Acad Sci U S A 69:1583-1586. CrossRef Medline

Steriade M, Datta S, Paré D, Oakson G, Curró Dossi RC (1990) Neuronal activities in brain-stem cholinergic nuclei related to tonic activation processes in thalamocortical systems. J Neurosci 10:2541-2559. Medline

Steriade M, Dossi RC, Nuñez A (1991) Network modulation of a slow intrinsic oscillation of cat thalamocortical neurons implicated in sleep delta waves: cortically induced synchronization and brainstem cholinergic suppression. J Neurosci 11:3200-3217. Medline

Steriade M, Amzica F, Nuñez A (1993) Cholinergic and noradrenergic modulation of the slow (approximately $0.3 \mathrm{~Hz}$ ) oscillation in neocortical cells. J Neurophysiol 70:1385-1400. Medline

Thakkar M, Portas C, McCarley RW (1996) Chronic low-amplitude electrical stimulation of the laterodorsal tegmental nucleus of freely moving cats increases REM sleep. Brain Res 723:223-227. CrossRef Medline

Thakkar MM, Strecker RE, McCarley RW (1998) Behavioral state control through differential serotonergic inhibition in the mesopontine cholinergic nuclei: a simultaneous unit recording and microdialysis study. J Neurosci 18:5490-5497. Medline

Van Dort CJ, Zachs DP, Kenny JD, Zheng S, Goldblum RR, Gelwan NA, Ramos DM, Nolan MA, Wang K, Weng FJ, Lin Y, Wilson MA, Brown EN (2015) Optogenetic activation of cholinergic neurons in the PPT or LDT induces REM sleep. Proc Natl Acad Sci U S A 112:584-589. CrossRef Medline

VanderHorst VG, Ulfhake B (2006) The organization of the brainstem and spinal cord of the mouse: relationships between monoaminergic, cholinergic, and spinal projection systems. J Chem Neuroanat 31:236. CrossRef Medline

Vong L, Ye C, Yang Z, Choi B, Chua S Jr, Lowell BB (2011) Leptin action on GABAergic neurons prevents obesity and reduces inhibitory tone to POMC neurons. Neuron 71:142-154. CrossRef Medline

Wang HL, Morales M (2009) Pedunculopontine and laterodorsal tegmental nuclei contain distinct populations of cholinergic, glutamatergic and GABAergic neurons in the rat. Eur J Neurosci 29:340-358. CrossRef Medline

Webster HH, Jones BE (1988) Neurotoxic lesions of the dorsal pontomesencephalic tegmentum-cholinergic cell area in the cat. ll. Effects upon sleep-waking states. Brain Res 458:285-302. CrossRef Medline

Woolf NJ, Butcher LL (1986) Cholinergic systems in the rat brain: III. Projections from the pontomesencephalic tegmentum to the thalamus, tectum, basal ganglia, and basal forebrain. Brain Res Bull 16:603637. CrossRef Medline 